NATIONAL LABORATORY

\title{
Neutron Resonance Parameters and Covariance Matrix of ${ }^{239} \mathrm{Pu}$
}

\section{September 2008}

\author{
Prepared by \\ H. Derrien \\ L. C. Leal \\ N. M. Larson
}

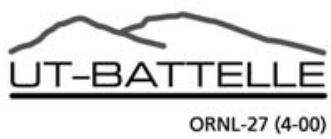




\title{
DOCUMENT AVAILABILITY
}

Reports produced after January 1, 1996, are generally available free via the U.S. Department of Energy (DOE) Information Bridge.

Web site http://www.osti.gov/bridge

Reports produced before January 1, 1996, may be purchased by members of the public from the following source.

\author{
National Technical Information Service \\ 5285 Port Royal Road \\ Springfield, VA 22161 \\ Telephone 703-605-6000 (1-800-553-6847) \\ TDD 703-487-4639 \\ Fax 703-605-6900 \\ E-mailinfo@ntis.gov \\ Web site http://www.ntis.gov/support/ordernowabout.htm
}

Reports are available to DOE employees, DOE contractors, Energy Technology Data Exchange (ETDE) representatives, and International Nuclear Information System (INIS) representatives from the following source.

Office of Scientific and Technical Information

P.O. Box 62

Oak Ridge, TN 37831

Telephone 865-576-8401

Fax 865-576-5728

E-mail reports@osti.gov

Web site http://www.osti.gov/contact.html

This report was prepared as an account of work sponsored by an agency of the United States Government. Neither the United States Government nor any agency thereof, nor any of their employees, makes any warranty, express or implied, or assumes any legal liability or responsibility for the accuracy, completeness, or usefulness of any information, apparatus, product, or process disclosed, or represents that its use would not infringe privately owned rights. Reference herein to any specific commercial product, process, or service by trade name, trademark, manufacturer, or otherwise, does not necessarily constitute or imply its endorsement, recommendation, or favoring by the United States Government or any agency thereof. The views and opinions of authors expressed herein do not necessarily state or reflect those of the United States Government or any agency thereof. 
ORNL/TM-2008/123

Nuclear Science and Technology Division

\title{
NEUTRON RESONANCE PARAMETERS AND CONVARIANCE MATRIX OF ${ }^{239} \mathrm{Pu}$
}

\author{
H. Derrien \\ L. C. Leal \\ N. M. Larson
}

Date Published: September 2008

\author{
Prepared by \\ OAK RIDGE NATIONAL LABORATORY \\ Oak Ridge, Tennessee 37831-6283 \\ managed by \\ UT-BATTELLE, LLC \\ for the \\ U.S. DEPARTMENT OF ENERGY \\ under contract DE-AC05-00OR22725
}





\section{CONTENTS}

Page

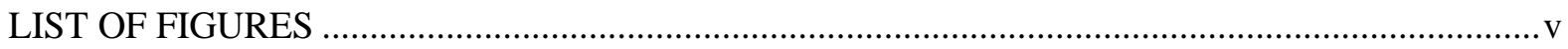

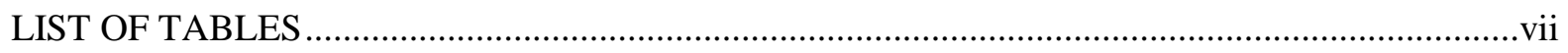

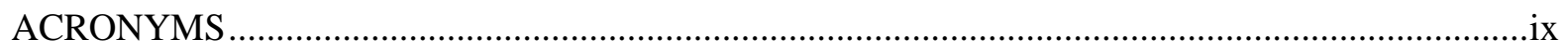

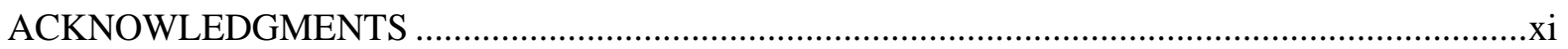

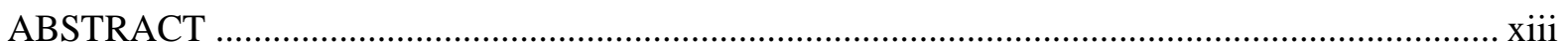

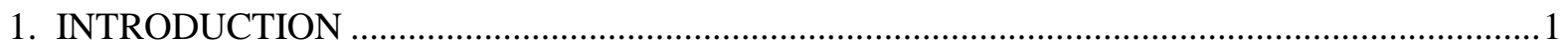

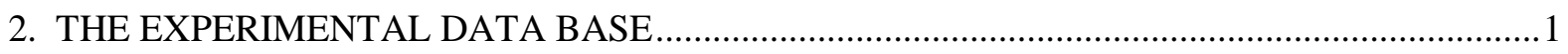

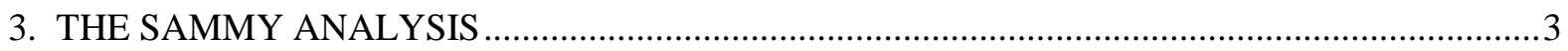

4. THE CALCULATED TRANSMISSIONS AND CROSS SECTIONS ….....................................

5. THE RESONANCE PARAMETER COVARIANCE MATRIX …........................................... 15

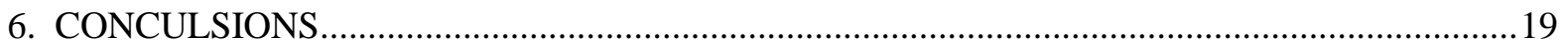

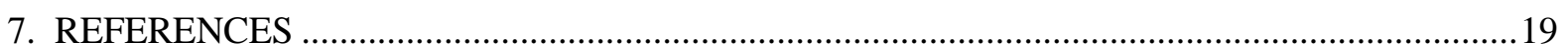





\section{LIST OF FIGURES}

Figure

Page

$1 \quad{ }^{239} \mathrm{Pu}$ capture cross section in the energy range 6 to $40 \mathrm{eV}$........................................... 10

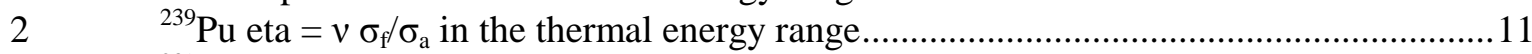

$3 \quad{ }^{239} \mathrm{Pu}$ neutron cross sections in the thermal energy range ...........................................11

$4 \quad{ }^{239} \mathrm{Pu}$ fission cross sections in the energy range 1 to $50 \mathrm{eV}$.......................................12

$5 \quad{ }^{239} \mathrm{Pu}$ fission cross sections in the energy range 30 to $100 \mathrm{eV}$....................................12

$6 \quad{ }^{239} \mathrm{Pu}$ fission cross sections in the energy range 300 to $400 \mathrm{eV}$.....................................13

$7 \quad{ }^{239} \mathrm{Pu}$ fission cross sections in the energy range 2000 to $2500 \mathrm{eV}$...................................13

$8 \quad{ }^{239} \mathrm{Pu}$ neutron transmission in the energy range 30 to $100 \mathrm{eV}$.......................................14

$9 \quad{ }^{239} \mathrm{Pu}$ neutron transmissions in the energy range 0.75 to $1.0 \mathrm{keV}$.................................... 14

$10 \quad{ }^{239} \mathrm{Pu}$ neutron transmission in the energy range 2.0 to $2.5 \mathrm{keV}$..................................... 15 



\section{LIST OF TABLES}

\section{Table}

Page

$1 \quad$ Selected measurements of ${ }^{239} \mathrm{Pu}$ neutron transmission and cross sections ..........................

$2 \quad{ }^{239} \mathrm{Pu}$ cross section at $0.0253 \mathrm{eV}$.

Average fission cross sections in selected low neutron energy ranges for the most recent experimental data, ENDF/B-6, and the present evaluation

4 Average fission cross sections in selected energy ranges for neutron energy between $0.1 \mathrm{keV}$ and $2.5 \mathrm{keV}$

5 Average capture cross sections in selected energy ranges for neutron energy below $100 \mathrm{eV}$.....

Average absorption and capture cross sections in selected energy ranges for neutron energy between 50 and $2500 \mathrm{eV}$.....

Group cross sections (b) and uncertainties calculated by PUFF-IV in the energy range $0.01 \mathrm{eV}$ to $2.5 \mathrm{keV}$

$10{ }^{239} \mathrm{Pu}$ average fission cross section (b) in energy ranges $E_{1}$ to $E_{2}(\mathrm{eV})$ and associated uncertainties

${ }^{239} \mathrm{Pu}$ average capture cross section (b) in energy ranges $\mathrm{E}_{1}$ to $\mathrm{E}_{2}(\mathrm{eV})$ and

associated uncertainties 



\section{ACRONYMS}

EALF Energy of Average Lethargy Causing Fission

ENDF Evaluated Nuclear Data Library

GELINA Geel Linear Accelerator

IAEA International Atomic Energy Agency

ORELA Oak Ridge Electron Linear Accelerator

ORNL Oak Ridge National Laboratory

rel. s. d. relative standard deviation

RPCM Resonance Parameter Covariance Matrix

TOF time-of-flight 



\section{ACKNOWLEDGMENTS}

The authors wish to thank Royce Sayer for helpful discussions regarding the use of the RSAP code and Joyce Echols for assistance with preparation of this document.

The work was sponsored by the U.S. Department of Energy Nuclear Criticality Safety Program (NCSP) under contract DE-AC05-00OR22725 with UT-Battelle, LLC. 



\begin{abstract}
In order to obtain the resonance parameters in a single energy range and the corresponding covariance matrix, a reevaluation of ${ }^{239} \mathrm{Pu}$ was performed with the code SAMMY. The most recent experimental data were analyzed or reanalyzed in the energy range thermal to $2.5 \mathrm{keV}$. The normalization of the fission cross section data was reconsidered by taking into account the most recent measurements of Weston et al. and Wagemans et al. A full resonance parameter covariance matrix was generated. The method used to obtain realistic uncertainties on the average cross section calculated by SAMMY or other processing codes was examined.
\end{abstract}





\section{INTRODUCTION}

In the years 1985-1993, the SAMMY analysis of the ${ }^{239} \mathrm{Pu}$ neutron transmission, fission cross section, and capture cross section experimental data was performed in the resolved resonance region up to $2500 \mathrm{eV}$ neutron energy. ${ }^{1-5}$ The resonance parameters obtained in this analysis were adopted in 1993 in the Evaluated Nuclear Data Library (ENDF)/B-VI. The evaluation was performed in three separated and uncorrelated energy ranges: 0 to $1 \mathrm{keV}, 1 \mathrm{keV}$ to $2 \mathrm{keV}$, and 2 to $2.5 \mathrm{keV}$. Due to the difficulties of handling large covariance matrices and inadequate format, the corresponding resonance parameter covariance file could not be used for ENDF/B-VI. Furthermore, the discrepancy between the average experimental fission cross sections in the energy range 0.1 to $1 \mathrm{keV}$ and the values obtained in the standard cross section evaluation ${ }^{6}$ was not solved before 1993 . $^{7,8}$ Recently, ${ }^{9}$ advancements made at Oak Ridge National Laboratory (ORNL) allowed the treatment of large resonance parameter covariance matrices by faster and larger computers with an improved version of the computer code SAMMY. ${ }^{10}$ The aim of the present work is to analyze an updated and renormalized experimental data base in order to obtain the resonance parameter covariance matrix in a single energy range of 0 to $2.5 \mathrm{keV}$.

\section{THE EXPERIMENTAL DATA BASE}

Most of the experimental data used in the present evaluation were taken at the Oak Ridge Electron Linear Accelerator (ORELA) between 1971 and 1993 by Gwin et al. ${ }^{11-13}$ for the fission and capture cross sections, by Weston et al. ${ }^{7,1-16}$ for the fission cross sections, and by Harvey et al. ${ }^{17,18}$ for the neutron transmissions. These data cover the energy range $0.01 \mathrm{eV}$ to $2.5 \mathrm{keV}$. The high resolution of Harvey transmission data ${ }^{18}$ and of Weston 1988 fission data ${ }^{7}$ allowed the resonance analysis to be performed in the energy range up to $2.5 \mathrm{keV}$. The fission cross section measurements performed by Wagemans et al. ${ }^{8,19}$ at Geel Linear Accelerator (GELINA) were used for normalization purpose. The only total cross section data available for the analysis in the thermal energy range are those from the measurement performed by Bollinger ${ }^{20}$ in 1956. The ORELA transmission data of Spencer et al., ${ }^{21}$ which were used in earlier evaluations, were not available for the present evaluation. The main features of the experimental data are summarized in Table 1.

Table 1. Selected measurements of ${ }^{239} \mathrm{Pu}$ neutron transmission and cross sections

\begin{tabular}{|c|c|c|c|}
\hline Reference & $\begin{array}{c}\text { Energy range } \\
(\mathrm{eV})\end{array}$ & Facility & Measurement characteristics \\
\hline Bollinger et al. $(1956)^{20}$ & 0.01 to 1.0 & & Total cross section; fast chopper \\
\hline Gwin et al. (1971) & 0.01 to 0.5 & ORELA & Fission and absorption at $25.6 \mathrm{~m}$ \\
\hline Gwin et al. (1976) ${ }^{12}$ & 1.0 to 100 . & ORELA & Fission and absorption at $40 \mathrm{~m}$ \\
\hline Gwin et al. $(1984)^{13}$ & 0.01 to 20.0 & ORELA & Fission at $8 \mathrm{~m}$ \\
\hline Weston et al. $(1984)^{15}$ & 9.0 to 2500 . & ORELA & Fission at $18.9 \mathrm{~m}$ \\
\hline Weston et al. $(1992)^{16}$ & 100.0 to 2500 . & ORELA & Fission at $86 \mathrm{~m}$ \\
\hline Weston et al. $(1993)^{7}$ & 0.02 to 40 & ORELA & Fission at $18.9 \mathrm{~m}$ \\
\hline Wagemans et al. $(1988)^{19}$ & 0.002 to 20.0 & GELINA & Fission at $8 \mathrm{~m}$ \\
\hline Wagemans et al. $(1993)^{8}$ & 0.01 to 1000.0 & GELINA & Fission at $8 \mathrm{~m}$ \\
\hline Harvey et al. $(1985)^{17}$ & 0.7 to 30 & ORELA & Transmission at $18 \mathrm{~m}$ \\
\hline Harvey et al. $(1988)^{18}$ & 30.0 to 2500 . & ORELA & Transmission at $80 \mathrm{~m}$ \\
\hline
\end{tabular}


All data were retrieved from the Brookhaven National Laboratory EXFOR file. ${ }^{22}$ In the previous evaluation, the neutron energy scale was defined by the neutron time-of-flight (TOF) of the $80 \mathrm{~m}$ flight path Harvey transmission data. All other TOF experiments were adjusted on this energy scale by a correction $\Delta E$ defined by the relation $\Delta E / E=a+b E^{1 / 2}, E$ being the neutron energy. This adjustment was kept in the present evaluation.

Measurements that include the thermal energy range can be normalized on the standard cross sections at the neutron energy $0.0253 \mathrm{eV}$. That is the case of Gwin 1971, 1976, and 1984 data, Wagemans 1988 and 1993 data, and Weston 1993 data. The other measurements, Weston 1984 and Weston 1988, should be normalized in an energy range overlapping with measurement normalized at $0.0253 \mathrm{eV}$. The normalization performed by Weston of his 1984 and 1988 data resulted in average fission cross sections 3 to $4 \%$ smaller than the values recommended by the ENDF/B-VI standard committee in the energy range 100 to $1000 \mathrm{eV}$. The fission measurement performed by Weston in 1993 was aimed at accurately determining the shape of the fission cross section down to $0.0253 \mathrm{eV}$ for a more accurate normalization of previously reported ORELA fission cross section measurements. The results indicate that 3\% higher normalization should have been used for the 1984 and 1988 fission data. At the same time, new measurements were also performed at GELINA by Wagemans et al. ${ }^{8}$ to address the ORELA data discrepancy; two different experiments were performed using different techniques. Wagemans obtained the value of $9277 \mathrm{~b} . e V$ for the fission integral in the energy range 100 to $1000 \mathrm{eV}$, which confirmed the 1993 results of Weston.

The problem of a normalization bias due to possible errors in the evaluation of the experimental background was not addressed by Weston, nor by Wagemans. The Weston 1984 fission cross section was renormalized by $3 \%$ compared to its original value. In the present work, a preliminary fit of the renormalized Weston 1984 data could be performed without background adjustment. A background was needed to fit the re-normalized Weston 1988 data; this background was $1.5 \mathrm{~b}$ ( $8 \%$ of the average cross section) at $100 \mathrm{eV}$ and about $0.3 \mathrm{~b}$ (7.5\% of the average cross section) at $2.5 \mathrm{keV}$. Therefore, before re-normalizing Weston 1988 fission data one should perform a background correction correlated to the normalization correction. These corrections were performed in the present evaluation prior to the final SAMMY fit of the data. The need for a background correction in the Weston 1988 fission cross section was already stressed by Derrien and de Saussure in Ref. 2, but the experimental basis for this necessary correction is not fully understood.

Experimental capture cross sections are available only from the Gwin et al. ${ }^{11,12}$ simultaneous fission and absorption measurements. The absorption data were contaminated with spurious resonances due to impurities in the samples and in the detector. The capture cross sections were obtained by the difference between the absorption and the fission cross sections and have large normalization and background uncertainties. The point-wise cross sections in the energy range $0.02 \mathrm{eV}$ to $2 \mathrm{keV}$, corresponding to the measurements available in Ref. 11 (1971 data), show a large gap in the energy range 1 to $7 \mathrm{eV}$. Only average cross sections are available from the 1976 measurements. ${ }^{12}$ In the energy range above $1 \mathrm{eV}$, the point-wise capture data were not included in the sequential SAMMY fits of the present evaluation. In general, the capture widths of the resonances could be obtained with good accuracy from analysis of the transmission and the fission experimental data. The capture data were only used to check the values of the capture widths in some uncertain cases. The contribution of the impurities in the energy range 0.02 to $1.0 \mathrm{eV}$ was calculated by Gwin et al. ${ }^{11}$ by using the result of a multilevel fit of the resonance at $0.3 \mathrm{eV}$; in the present evaluation, the experimental data were corrected for this contribution and renormalized to the standard value at $0.0253 \mathrm{eV}$.

Finally, after re-normalization, adjustment of the neutron energy on the same energy scale, and some background reevaluation, a consistent experimental data base was obtained that was suitable for a 
sequential SAMMY analysis in the energy range $0.001 \mathrm{eV}$ to $2.5 \mathrm{keV}$. The other experimental parameters, such as the resolution and Doppler broadening parameters, were taken from the earlier evaluation. ${ }^{1-5}$

\section{THE SAMMY ANALYSIS}

The three independent sets of resonance parameters of ENDF/B-VI were merged in a single set by suppressing the external resonances in the boundaries of the sets, keeping only the external negative resonances and the external resonances above $2.5 \mathrm{keV}$. Since the three ENDF/B-VI parameter sets were obtained from uncorrelated evaluation, it was not expected that this single set could accurately fit the experimental data base. Actually, the total and fission cross section at $0.0253 \mathrm{eV}$ obtained with the single set was 1087 and $808 \mathrm{~b}$, respectively, which is far from the standard values of 1027 and $748 \mathrm{~b}$. Furthermore, the average neutron transmissions calculated with the single set deviated from the Harvey experimental values by 2 to $5 \%$ in some energy ranges, which is not consistent with the accuracy of less than $1 \%$ of Harvey experimental normalization. A new set of external resonance parameters had to be evaluated. From preliminary SAMMY fits, the parameters of two large fictitious negative energy resonances at $-0.805 \mathrm{keV}\left(0^{+}\right.$resonance) and $-0.795 \mathrm{keV}\left(1^{+}\right.$resonance), and of two large fictitious resonances above $2.5 \mathrm{keV}$, at $3.295 \mathrm{keV}\left(1^{+}\right.$resonance) and at $3.305 \mathrm{keV}$ $\left(0^{+}\right.$resonance), were obtained that permitted reproduction of the Harvey transmission data within the experimental accuracy. These fictitious resonances simulate the s-wave neutron strength function over an energy range of about $2.5 \mathrm{keV}$ below $0 \mathrm{eV}$ and above $2.5 \mathrm{keV}$. The effective scattering radius $R^{\prime}=9.41 \mathrm{fm}$ was kept from the previous evaluation.

Three fictitious bound resonances in the energy range -5 to $0 \mathrm{eV}$ were used to adjust the cross sections at $0.0253 \mathrm{eV}$. The $0^{+}$resonance at $-4.4 \mathrm{eV}$ can be used for small variation of the calculated capture and fission cross sections at $0.0253 \mathrm{eV}$. A variation of $0.37 \%$ of the capture cross section is obtained by a variation of $3.4 \%$ of the capture width, with negligible effect on the fission cross section, and a variation of $0.13 \%$ of the fission cross section is obtained by a variation of $0.48 \%$ of the neutron width, with very little effect on the capture cross section. The very small $1^{+}$resonance at $-0.1 \mathrm{eV}$ can be used to modify the shape of the cross sections in the thermal range. The capture widths of the resonances at $-4.4 \mathrm{eV}$ and $-0.27 \mathrm{eV}$ are $150.7 \mathrm{meV}$ and $4.2 \mathrm{meV}$, respectively, which are not consistent with the average value. Actually, due to the interference effect in the fission channels, the fission cross section in the thermal range is strongly correlated to the minimum of the cross sections at $7 \mathrm{eV}$. The parameters of these fictitious resonances allow a good representation of the cross sections at thermal and at $7 \mathrm{eV}$.

The SAMMY analysis was performed in three stages. The first stage included Bollinger total cross section, Gwin 1971 fission and capture cross sections, Gwin 1984 fission cross section, Wagemans 1988 fission cross section, and Weston 1993 fission cross section, in the energy range 0.01 to $7 \mathrm{eV}$, with the data normalized to the cross sections at $0.0253 \mathrm{eV}$. The second stage was performed in the energy range 0.6 to $40 \mathrm{eV}$, including Harvey neutron transmission, Weston 1984 fission cross sections, Gwin 1984 fission cross sections, and Weston 1993 fission cross sections. The third stage was performed in the energy range 30 to $2500 \mathrm{eV}$, including Harvey transmission data, Weston 1984 fission cross section, and Weston 1988 fission cross section. The experimental fission data were normalized to the integral value of $9277 \mathrm{~b} . \mathrm{eV}$ recommended by Wagemans in the energy range 100 to $1000 \mathrm{eV}$. In each stage the cross section and transmission were calculated with the entire set of parameters. The experimental data base contained a total number of 110,696 measured values. The $\chi^{2}$ value corresponding to the final set of resonance parameters was 1.31 per data point. 
Better fits of the fission cross sections were obtained with two $1^{+}$fission channels, in the energy range below $30 \mathrm{eV}$ where the interference effects between resonances are not washed out by the experimental resolution. Only a single $1^{+}$fission channel was used in the previous evaluations. Actually, there is no $1^{+}$state in the simple collective bands of the deformed ${ }^{240} \mathrm{Pu}$ nucleus. As it was shown by Griffin, ${ }^{23}$ at least one $1^{+}$state could be found by combination of two octopole vibration states, but it is also possible that another $1^{+}$state could be found from other combinations.

The new set of resonance parameters contains 1030 s-wave resonances for the description of the cross sections in the energy range 0 to $2.5 \mathrm{keV}$. As for the previous evaluations, no attempt was made to identify possible p-wave resonances. All the resonances for which the capture width could not be determined with good accuracy from the SAMMY analysis were assigned the value of $39 \mathrm{meV}$, which is close to the average value, $40.6 \mathrm{meV}$, of the 152 values which were determined by the final SAMMY fits. The statistical properties of the parameters are very close to those described in Refs. 1-5 and will not be examined in the present report.

\section{THE CALCULATED TRANSMISSIONS AND CROSS SECTIONS}

The cross sections at $0.0253 \mathrm{eV}$ calculated with the resonance parameters are shown in Table 2 and compared to the standard values, to ENDF/B-VI, and to the most recent Mughabghab ${ }^{24}$ recommendation. Small variations of the thermal cross sections have a large impact on the calculation of $\mathrm{k}_{\text {eff }}$ of thermal assemblies. From several benchmark calculations it is possible to adjust the thermal cross sections to the most recommendable values. The values shown in the last column of Table 2 were adjusted from benchmark calculations of $k_{\text {eff }}$ of several thermal assemblies.

The average fission cross sections calculated with the present resonance parameters are displayed in Tables 3 and 4 in the energy ranges thermal to $100 \mathrm{eV}$ and 100 to $2500 \mathrm{eV}$, respectively. The experimental data of Gwin, Weston, and Wagemans and the values calculated from ENDF/B-VI are also shown for comparison. As expected, the differences between the present evaluation and ENDF/B-VI are small, less than $1 \%$ when averaged over wide energy ranges.

Table 2. ${ }^{239} \mathrm{Pu}$ cross section at $0.0253 \mathrm{eV}$

\begin{tabular}{lcccc}
\hline & $\begin{array}{c}\text { Standard } \\
\mathbf{1 9 9 2}\end{array}$ & $\begin{array}{c}\text { B-VI } \\
\mathbf{1 9 9 3}\end{array}$ & $\begin{array}{c}\text { Mughabghab } \\
\mathbf{2 0 0 5}\end{array}$ & $\begin{array}{c}\text { Present } \\
\mathbf{2 0 0 7}\end{array}$ \\
\hline Total (b) & $(1027.30)$ & 1026.30 & $1025.3 \pm 2.9$ & 1027.30 \\
Fission (b) & $747.99 \pm 0.25$ & 747.66 & $748.1 \pm 2.0$ & 747.09 \\
Capture (b) & $271.43 \pm 0.79$ & 270.65 & $269.3 \pm 2.9$ & 271.40 \\
Scattering (b) & $7.88 \pm 12.30$ & 7.99 & $7.94 \pm 0.4$ & 8.81 \\
\hline
\end{tabular}


Table 3. Average fission cross sections in selected low neutron energy ranges for the most recent experimental data, ENDF/B-6, and the present evaluation ${ }^{a}$

\begin{tabular}{cccccccc}
\hline $\begin{array}{c}\text { Energy } \\
\text { Range } \\
(\mathbf{e V})\end{array}$ & $\begin{array}{c}\text { Weston } \\
\mathbf{1 9 8 4}\end{array}$ & $\begin{array}{c}\text { Gwin } \\
\mathbf{1 9 8 4}\end{array}$ & $\begin{array}{c}\text { Wagemans } \\
\mathbf{1 9 8 8}\end{array}$ & $\begin{array}{c}\text { Weston } \\
\mathbf{1 9 9 3}\end{array}$ & $\begin{array}{c}\text { ENDF/B-6 } \\
\mathbf{1 9 9 3}\end{array}$ & $\begin{array}{c}\text { Present } \\
\mathbf{2 0 0 7}\end{array}$ & $\begin{array}{c}\text { Percent } \\
\text { deviation }\end{array}$ \\
\hline $0.01-0.02$ & & 969.9 & 970.6 & 974.0 & 971.3 & 971.6 & -0.3 \\
$0.02-0.03$ & & 752.5 & 754.4 & 756.0 & 755.5 & 755.0 & -0.0 \\
$0.03-0.04$ & & 645.1 & 652.1 & 648.5 & 647.7 & 647.2 & -0.1 \\
$0.04-0.05$ & & 578.4 & 584.9 & 581.7 & 582.4 & 582.4 & 0.0 \\
$0.05-0.10$ & & 497.8 & 498.7 & 497.8 & 499.3 & 501.7 & +0.5 \\
$0.10-0.20$ & & 582.8 & 586.7 & 588.2 & 586.1 & 594.8 & +1.5 \\
$0.20-0.30$ & & 1995. & 2030. & 2035. & 2015. & 2009. & -0.3 \\
$0.30-0.40$ & & 1684. & 1708. & 1695. & 1689. & 1693. & +0.2 \\
$0.40-0.50$ & & 349.4 & 346.1 & 347.0 & 348.0 & 341.0 & -2.1 \\
$0.50-1.00$ & & 76.3 & 77.9 & 75.1 & 77.4 & 76.2 & -1.6 \\
$1.00-6.00$ & & 12.1 & 12.1 & 11.5 & 11.6 & 11.7 & +0.9 \\
$6.00-10.0$ & & 46.2 & 47.8 & 46.7 & 46.3 & 47.9 & +3.5 \\
\hline $0.01-10.0$ & & 79.93 & 81.31 & 80.34 & 80.10 & 80.73 & +0.8 \\
\hline $10.0-12.6$ & 188.8 & 191.8 & 191.7 & 190.3 & 191.5 & 192.3 & +0.4 \\
$12.6-20.0$ & 74.0 & 74.7 & 74.0 & 73.7 & 72.6 & 73.9 & +1.8 \\
$21.0-24.7$ & 48.2 & 46.3 & & 48.0 & 46.8 & 47.0 & +0.4 \\
$24.7-30.0$ & 18.9 & 18.6 & & 18.7 & 18.2 & 18.0 & -1.1 \\
$30.0-55.0$ & 17.5 & & & 17.4 & 17.7 & 17.6 & +1.1 \\
$55.0-80.0$ & 71.9 & & & 72.3 & 72.0 & 71.0 & -1.4 \\
$80.0-100$. & 48.8 & & & 49.2 & 48.9 & 48.6 & -0.6 \\
\hline $0.01-100$. & & & & 53.9 & 53.7 & 53.6 & -0.2 \\
$10.0-100$. & 50.86 & & & 50.99 & 50.78 & 50.54 & -0.5 \\
\hline
\end{tabular}

${ }^{a}$ The last column shows the percentage deviation between the present evaluation and ENDF/B-VI. The cross sections are given in barns. The average cross sections were calculated with the code SAMMY. 
Table 4. Average fission cross sections in selected energy ranges for neutron energy between $0.1 \mathrm{keV}$ and $2.5 \mathrm{keV}^{a}$

\begin{tabular}{ccccccc}
\hline $\begin{array}{c}\text { Energy } \\
\text { range } \\
\text { (keV) }\end{array}$ & $\begin{array}{c}\text { Weston } \\
\mathbf{1 9 8 4}\end{array}$ & $\begin{array}{c}\text { Weston } \\
\mathbf{1 9 8 8}\end{array}$ & $\begin{array}{c}\text { Standard } \\
\mathbf{1 9 9 0}\end{array}$ & $\begin{array}{c}\text { ENDF/B-6 } \\
\mathbf{1 9 9 3}\end{array}$ & $\begin{array}{c}\text { Present } \\
\mathbf{2 0 0 7}\end{array}$ & $\begin{array}{c}\text { Percent } \\
\text { deviation }\end{array}$ \\
\hline $0.10-0.20$ & 18.50 & 19.00 & 19.00 & 18.69 & 18.41 & -1.5 \\
$0.20-0.30$ & 17.82 & 17.83 & 17.83 & 17.80 & 17.67 & -0.7 \\
$0.30-0.40$ & 8.313 & 8.203 & 8.203 & 8.301 & 8.268 & -0.4 \\
$0.40-0.50$ & 9.546 & 9.403 & 9.403 & 9.580 & 9.447 & -1.4 \\
$0.50-0.60$ & 15.51 & 15.31 & 15.31 & 15.40 & 15.36 & -0.3 \\
$0.60-0.70$ & 4.285 & 4.189 & 4.189 & 4.358 & 4.278 & -1.9 \\
$0.70-0.80$ & 5.507 & 5.502 & 5.502 & 5.509 & 5.525 & +0.3 \\
$0.80-0.90$ & 4.872 & 4.873 & 4.873 & 4.842 & 4.877 & +0.7 \\
$0.90-1.00$ & 8.361 & 8.437 & 8.437 & 8.436 & 8.424 & -0.1 \\
\hline $0.10-1.00$ & 10.30 & 10.31 & 10.37 & 10.32 & 10.25 & -0.7 \\
\hline $1.00-1.10$ & 5.657 & 5.564 & & 5.551 & 5.488 & -1.1 \\
$1.10-1.20$ & 6.026 & 6.118 & & 5.975 & 5.960 & -0.3 \\
$1.20-1.30$ & 4.466 & 4.684 & & 4.592 & 4.496 & -2.1 \\
$1.30-1.40$ & 7.331 & 7.299 & & 6.980 & 7.253 & +3.9 \\
$1.40-1.50$ & 3.943 & 4.130 & & 4.033 & 3.984 & -1.2 \\
$1.50-1.60$ & 2.422 & 2.583 & & 2.555 & 2.435 & -4.9 \\
$1.60-1.70$ & 3.830 & 4.075 & & 3.944 & 3.890 & -1.4 \\
$1.70-1.80$ & 3.204 & 3.513 & & 3.387 & 3.340 & -1.4 \\
$1.80-1.90$ & 5.315 & 5.448 & & 5.165 & 5.307 & +2.7 \\
$1.90-2.00$ & 1.996 & 2.139 & & 2.155 & 1.960 & -9.9 \\
\hline $1.00-2.00$ & 4.419 & 4.555 & 4.466 & 4.432 & 4.419 & -0.3 \\
\hline $2.00-2.10$ & 1.983 & 2.014 & & 2.033 & 1.947 & -4.4 \\
$2.10-2.20$ & 3.028 & 3.029 & & 2.942 & 2.988 & +1.6 \\
$2.20-2.30$ & 2.399 & 2.342 & & 2.351 & 2.242 & -4.9 \\
$2.30-2.40$ & 3.534 & 3.715 & & 3.637 & 3.636 & -0.0 \\
$2.40-2.50$ & 4.118 & 4.050 & & 3.961 & 4.034 & +1.8 \\
\hline $2.00-2.50$ & 3.012 & 3.030 & & 2.985 & 2.968 & -0.6 \\
\hline
\end{tabular}

${ }^{a}$ Weston 1984 data and Weston 1988 data, ENDF/B-6, and the results of the present analysis are displayed in the table. Weston 1984 data and Weston 1988 data were normalized to the integral standard proposed by Wagemans in 1993 . The last column shows the percentage deviation between ENDF/B-6 and the present evaluation. The cross sections are given in barns. The average cross sections were calculated with the code SAMMY.

The average capture and absorption cross sections are displayed in Table 5 in the energy range 0.02 to $100 \mathrm{eV}$, and in Table 6 in the energy range 0.05 to $2.5 \mathrm{keV}$, along with the data calculated with the present resonance parameters and those calculated from ENDF/B-VI. In the thermal energy range, the experimental capture data and the calculated values agree in general within $1 \%$. In the energy range 7 to $100 \mathrm{eV}$, the evaluated data are significantly smaller than Gwin 1971. The differences could be due to the uncertainties in background and impurities contribution corrections in the experimental data, as it is shown in Fig. 1. In the energy range 0.10 to $1.0 \mathrm{keV}$, the calculated capture cross section is, on average, $7 \%$ smaller than Gwin 1976. It is likely that the absorption cross sections inferred from the very accurate Harvey transmission measurements are more reliable than the Gwin measurements which needed important background and impurities corrections. Note that the calculated capture data agree within $1.3 \%$, on average, with Schomberg ${ }^{25}$ measured values in the energy range 0.10 to $1 \mathrm{keV}$. In the energy range 1 to $2 \mathrm{keV}$, the calculated cross section is between the Schomberg and the Gwin values. 
Table 5. Average capture cross sections in selected energy ranges for neutron energy below $100 \mathrm{eV}^{a}$

\begin{tabular}{ccccccc}
\hline $\begin{array}{c}\text { Energy } \\
\text { range } \\
(\mathbf{e V})\end{array}$ & Gwin 1971 & Gwin 1976 & $\begin{array}{c}\text { Gwin } \\
\text { EXFOR }\end{array}$ & $\begin{array}{c}\text { ENDF/B-6 } \\
\mathbf{1 9 9 6}\end{array}$ & $\begin{array}{c}\text { Present } \\
\mathbf{2 0 0 7}\end{array}$ & $\begin{array}{c}\text { Percent } \\
\text { deviation }\end{array}$ \\
\hline $0.02-0.03$ & 273. & 282. & 267. & 272.9 & 273.7 & +0.3 \\
$0.03-0.04$ & 244. & 246. & 238. & 245.1 & 245.3 & +0.2 \\
$0.04-0.05$ & 231. & 227. & 226. & 230.7 & 230.5 & -0.1 \\
$0.05-0.06$ & 226. & 226. & 222. & 233.5 & 223.0 & -0.2 \\
$0.06-0.07$ & 223. & 222. & 218. & 221.1 & 220.2 & -0.4 \\
$0.07-0.08$ & 226. & 213. & 221. & 222.1 & 221.0 & -0.5 \\
$0.08-0.09$ & 230. & 227. & 225. & 226.1 & 224.7 & -0.6 \\
$0.10-0.20$ & 236. & 236. & 231. & 232.7 & 231.1 & -0.7 \\
$0.20-0.30$ & 350. & 347. & 346. & 347.6 & 343.4 & -1.2 \\
$0.30-0.40$ & 1363. & 1359. & 1354. & 1362.6 & 1342.8 & -1.5 \\
$0.40-0.50$ & 1152. & 1139. & 1089. & 1090.0 & 1105.2 & +1.4 \\
$0.50-0.60$ & 203. & 204. & 191. & 190.0 & 192.2 & +1.2 \\
$0.60-0.70$ & 69. & 68. & 65. & 66.4 & 66.8 & +0.6 \\
& 33. & 34. & 33. & 33.8 & 33.9 & +0.3 \\
\hline $0.02-0.70$ & 493.9 & 491.0 & 479.9 & 482.8 & 481.1 & -0.4 \\
\hline $0.70-7.30$ & & & & 3.12 & 2.91 & -7.2 \\
$7.30-16.0$ & $88.5 \pm 15$. & & & 76.4 & 74.3 & -3.0 \\
$16.0-37.5$ & $22.0 \pm 4.0$ & & & 20.5 & 20.7 & +1.0 \\
$37.5-50.0$ & $62.4 \pm 6.0$ & & & 48.6 & 49.7 & +2.3 \\
$50.0-100$. & $37.3 \pm 6.0$ & & & 33.6 & 34.5 & +2.7 \\
\hline
\end{tabular}

${ }^{a}$ The last column shows the percentage deviation between ENDF/B-6 and the present evaluation. The data labeled Gwin EXFOR come from the only Gwin experimental data compiled in the CSISRS library, corrected for the impurity contributions in the energy range below $0.7 \mathrm{eV}$ in the present evaluation. The data labeled Gwin 1971 and Gwin 1976 are those of Refs. 11 and 12 renormalized at $0.0253 \mathrm{eV}$. In the energy range above $7.3 \mathrm{eV}$, the differences between the experimental data and the evaluated data are due to an important remaining background in the experimental data (Fig. 3). The cross sections are given in barns. The average cross sections were calculated with the code SAMMY. 
Table 6. Average absorption and capture cross sections in selected energy ranges for neutron energy between 50 and $2500 \mathrm{eV}^{a}$

\begin{tabular}{ccccccrrr}
\hline $\begin{array}{c}\text { Energy } \\
\text { range } \\
(\mathbf{k e V})\end{array}$ & $\begin{array}{c}\text { Gwin } \\
\text { Abs. } \\
\mathbf{( 1 9 7 6 )}\end{array}$ & $\begin{array}{c}\text { ENDF/B-6 } \\
\text { Abs. }\end{array}$ & $\begin{array}{c}\text { Present } \\
\text { Abs. }\end{array}$ & $\begin{array}{c}\text { Shomberg } \\
\text { Capt. } \\
\mathbf{( 1 9 7 0 )}\end{array}$ & $\begin{array}{c}\text { Gwin } \\
\text { Capt. } \\
(\mathbf{1 9 7 6})\end{array}$ & $\begin{array}{c}\text { ENDF/B-6 } \\
\text { Capt. }\end{array}$ & $\begin{array}{c}\text { Present } \\
\text { Capt. }\end{array}$ & $\begin{array}{c}\text { Percent } \\
\text { difference }\end{array}$ \\
\hline $0.05-0.10$ & 92.84 & & 92.35 & & 35.88 & 33.60 & 34.00 & +1.2 \\
$0.10-0.20$ & 33.66 & 34.22 & 33.59 & 17.81 & 15.70 & 15.53 & 15.18 & -2.3 \\
$0.20-0.30$ & 34.69 & 35.59 & 32.70 & 14.86 & 16.79 & 15.74 & 15.02 & -4.8 \\
$0.30-0.40$ & 18.31 & 17.95 & 17.36 & 9.90 & 9.83 & 9.65 & 9.10 & -6.0 \\
$0.40-0.50$ & 13.56 & 13.52 & 13.30 & 4.29 & 4.16 & 3.94 & 3.85 & -2.3 \\
$0.50-0.60$ & 26.54 & 26.23 & 25.95 & 9.88 & 11.08 & 10.83 & 10.59 & -2.3 \\
$0.60-0.70$ & 11.57 & 10.86 & 10.85 & 6.91 & 7.02 & 6.50 & 6.57 & +1.1 \\
$0.70-0.80$ & 10.52 & 10.43 & 10.23 & 5.16 & 5.18 & 4.92 & 4.71 & -4.5 \\
$0.80-0.90$ & 9.30 & 8.47 & 8.56 & 2.85 & 4.20 & 3.63 & 3.69 & +1.3 \\
$0.90-1.00$ & 13.23 & 13.48 & 13.55 & 4.42 & 5.40 & 5.04 & 5.12 & +1.6 \\
\hline $0.10-1.00$ & 19.04 & 18.75 & 18.42 & 8.31 & 8.81 & 8.43 & 8.20 & -2.8 \\
\hline $1.00-1.10$ & & 10.26 & 9.83 & & & 4.71 & 4.34 & -8.5 \\
$1.10-1.20$ & & 9.71 & 9.58 & & & 3.74 & 3.62 & -3.5 \\
$1.20-1.30$ & & 8.86 & 8.56 & & & 4.26 & 4.06 & -4.9 \\
$1.30-1.40$ & & 9.98 & 9.92 & & & 3.00 & 2.67 & -12. \\
$1.40-1.50$ & & 7.46 & 7.36 & & & 3.43 & 3.38 & -1.5 \\
$1.50-1.60$ & & 6.05 & 5.90 & & & 3.50 & 3.47 & -0.9 \\
$1.60-1.70$ & & 7.75 & 7.61 & & & 3.81 & 3.72 & -2.4 \\
$1.70-1.80$ & & 7.45 & 7.30 & & & 4.07 & 3.96 & -2.8 \\
$1.80-1.90$ & & 8.78 & 8.76 & & & 3.62 & 3.46 & -4.6 \\
$1.90-2.00$ & & 5.39 & 5.22 & & & 3.23 & 3.25 & +0.6 \\
\hline $1.00-2.00$ & 8.31 & 8.18 & 8.00 & 3.25 & 3.79 & 3.74 & 3.59 & -4.2 \\
\hline $2.00-2.50$ & & 6.44 & 6.13 & & & 3.46 & 3.16 & -9.5 \\
\hline
\end{tabular}

${ }^{a}$ Data from Gwin 1976 are given and compared to ENDF/B-6 and the present evaluation. The last column shows the percentage difference between ENDF/B-6 and the present evaluation. The average capture cross sections in the present evaluation are generally lower than those calculated from ENDF/B-6 and significantly lower than Gwin 1976 values. The difference between the present values and Gwin values are mainly due to different absorption cross sections.

The dilute capture resonance integral values of ENDF/B-VI and of the present evaluation are displayed in Table 7 in several energy ranges. By adding the contribution of ENDF/B-VI in the energy range $2.5 \mathrm{keV}$ to $20 \mathrm{MeV}$, one obtains, in the energy range $0.5 \mathrm{eV}$ to $20 \mathrm{MeV}$, the value of $179.74 \mathrm{~b}$ for the present evaluation compared to the value of $181.54 \mathrm{~b}$ for ENDF/B-VI and $180 \pm 20 \mathrm{~b}$ from Mughabghab ${ }^{24}$ recommendations.

The averaged experimental neutron transmissions of Harvey are compared to the values calculated with the resonance parameters in Table 8 . The difference of $0.5 \%$ over the energy range 0.030 to $2.5 \mathrm{keV}$ between the thick sample experimental data and the calculated values corresponds to $0.07 \mathrm{~b}$ of the total cross section, which is $0.6 \%$ of the potential scattering cross section. 
Table 7. Capture resonance integral in selected energy range

\begin{tabular}{cccc}
\hline $\begin{array}{c}\text { Energy range } \\
(\mathbf{e V})\end{array}$ & $\begin{array}{c}\text { ENDF/B-VI } \\
\text { (barn) }\end{array}$ & $\begin{array}{c}\text { Present } \\
\text { (barn) }\end{array}$ & $\begin{array}{c}\text { Percentage } \\
\text { difference } \\
(\boldsymbol{\%})\end{array}$ \\
\hline $0.01-0.10$ & 626.7 & 627.7 & +0.2 \\
$0.10-0.30$ & 777.9 & 767.5 & -1.4 \\
$0.30-0.50$ & 371.1 & 376.1 & +1.3 \\
\hline $0.01-0.50$ & 1775.7 & 1771.3 & -0.2 \\
\hline $0.50-0.70$ & 17.58 & 17.67 & +0.5 \\
$0.70-7.00$ & 11.82 & 11.32 & -4.4 \\
$7.00-100$. & 118.26 & 117.91 & -0.3 \\
$100 .-1000$. & 26.09 & 25.26 & -3.3 \\
$1000 .-2000$. & 2.62 & 2.51 & -4.4 \\
$2000 .-2500$. & 0.77 & 0.71 & -8.5 \\
\hline $0.5-2500$. & 177.09 & 175.29 & -1.0 \\
\hline
\end{tabular}

Table 8. J. A. Harvey ${ }^{18}$ average ${ }^{239}$ Pu neutron transmissions for three sample thicknesses ${ }^{a}$

\begin{tabular}{|c|c|c|c|c|c|c|c|c|c|}
\hline \multirow{2}{*}{$\begin{array}{c}\text { Energy range } \\
(\mathrm{keV})\end{array}$} & \multicolumn{3}{|c|}{$0.074 \mathrm{at} / \mathrm{b}$} & \multicolumn{3}{|c|}{$0.018 \mathrm{at} / \mathrm{b}$} & \multicolumn{3}{|c|}{$0.0064 \mathrm{at} / \mathrm{b}$} \\
\hline & exp. & Theory & $(\%)$ & exp. & Theory & $(\%)$ & exp. & Theory & $(\%)$ \\
\hline $0.006-0.030$ & 0.1760 & 0.1790 & +1.7 & 0.5240 & 0.5240 & -0.0 & 0.7200 & 0.7190 & -0.1 \\
\hline $0.030-0.100$ & 0.1511 & 0.1523 & +0.8 & 0.4990 & 0.4960 & -0.6 & 0.7240 & 0.7200 & -0.6 \\
\hline $0.100-0.200$ & 0.2047 & 0.2075 & +1.4 & 0.6027 & 0.6004 & -0.4 & 0.8042 & 0.8001 & -0.6 \\
\hline $0.200-0.400$ & 0.2132 & 0.2122 & -0.5 & 0.6183 & 0.6160 & -0.4 & 0.8149 & 0.8136 & -0.5 \\
\hline $0.400-0.600$ & 0.2162 & 0.2154 & -0.4 & 0.6265 & 0.6241 & -0.4 & 0.8263 & 0.8248 & -0.2 \\
\hline $0.600-0.800$ & 0.2639 & 0.2641 & +0.1 & 0.6838 & 0.6826 & -0.6 & 0.8643 & 0.8637 & -0.1 \\
\hline $0.800-1.000$ & 0.2669 & 0.2669 & -0.0 & 0.6836 & 0.6828 & -0.1 & 0.8632 & 0.8625 & -0.1 \\
\hline $1.000-1.200$ & 0.2691 & 0.2675 & -0.6 & 0.6831 & 0.6838 & +0.1 & 0.8656 & 0.8657 & +0.0 \\
\hline $1.200-1.400$ & 0.2655 & 0.2636 & -0.7 & 0.6886 & 0.6890 & +0.1 & 0.8712 & 0.8702 & -0.1 \\
\hline $1.400-1.600$ & 0.2928 & 0.2918 & -0.3 & 0.7164 & 0.7168 & +0.1 & 0.8852 & 0.8853 & +0.0 \\
\hline $1.600-1.800$ & 0.2902 & 0.2901 & -0.0 & 0.7038 & 0.7045 & +0.1 & 0.8753 & 0.8765 & +0.1 \\
\hline $1.800-2.000$ & 0.2794 & 0.2781 & -0.5 & 0.7000 & 0.7007 & +0.1 & 0.8766 & 0.8464 & -0.0 \\
\hline $2.000-2.250$ & 0.2986 & 0.2974 & -0.4 & 0.7261 & 0.7226 & -0.5 & 0.8925 & 0.8886 & -0.4 \\
\hline $2.250-2.500$ & 0.2842 & 0.2786 & -2.0 & 0.7058 & 0.7045 & -0.2 & 0.8784 & 0.8792 & +0.3 \\
\hline $0.030-2.500$ & 0.2624 & 0.2612 & -0.5 & 0.6775 & 0.6788 & +0.1 & 0.8580 & 0.8581 & -0.0 \\
\hline
\end{tabular}

${ }^{a}$ The experimental values (exp.) are compared to the values calculated with the resonance parameters (theory). An error of $1 \%$ on the thick sample transmission corresponds to $0.135 \mathrm{~b}$ in the total cross section, which is about $1 \%$ of the potential scattering cross section. The percentage deviations between the experimental values and the theoretical values are also given. 
Examples of SAMMY fits are given in Figs. 1 to 10. The experimental data and the corresponding values calculated with the resonance parameters are displayed. The results of $\eta=v \sigma_{a} / \sigma_{f}$ measurements ${ }^{26-32}$ are given in Fig. 2; the experimental data were normalized to the area of the curve calculated with the resonance parameters and the values of $v$ (average number of neutron emitted by fission) taken in JEF/DOC-1158. ${ }^{33}$ The fits of the thermal data and of the resonance at $0.3 \mathrm{eV}$ are shown in Fig. 3. Gwin 1971 capture cross sections are shown in Fig. 1 in the energy range 7 to $40 \mathrm{eV}$. The experimental data were not corrected for the tungsten isotope resonance contributions. The discrepancy between the resonances is likely due to an important residual background in the experimental data. Figures 4 and 5 show the most recent experimental fission cross sections in the energy range up to $100 \mathrm{eV}$. The low values of the experimental cross sections near $30 \mathrm{eV}$ and near $38 \mathrm{eV}$ are not well represented by the resonance parameters. The errors on these measured low cross sections could be important due the uncertainties on the background evaluation. Examples of fits of Weston 84 and Weston 88 fission data are given in Figs. 6 and 7 in the energy range 300 to $400 \mathrm{eV}$ and 2.0 to $2.5 \mathrm{keV}$, respectively. Figures 8 to 10 show the fits to Harvey transmission data in the energy ranges 30 to $100 \mathrm{eV}, 750$ to $1000 \mathrm{eV}$, and $2.0 \mathrm{keV}$ to $2.5 \mathrm{keV}$, respectively.

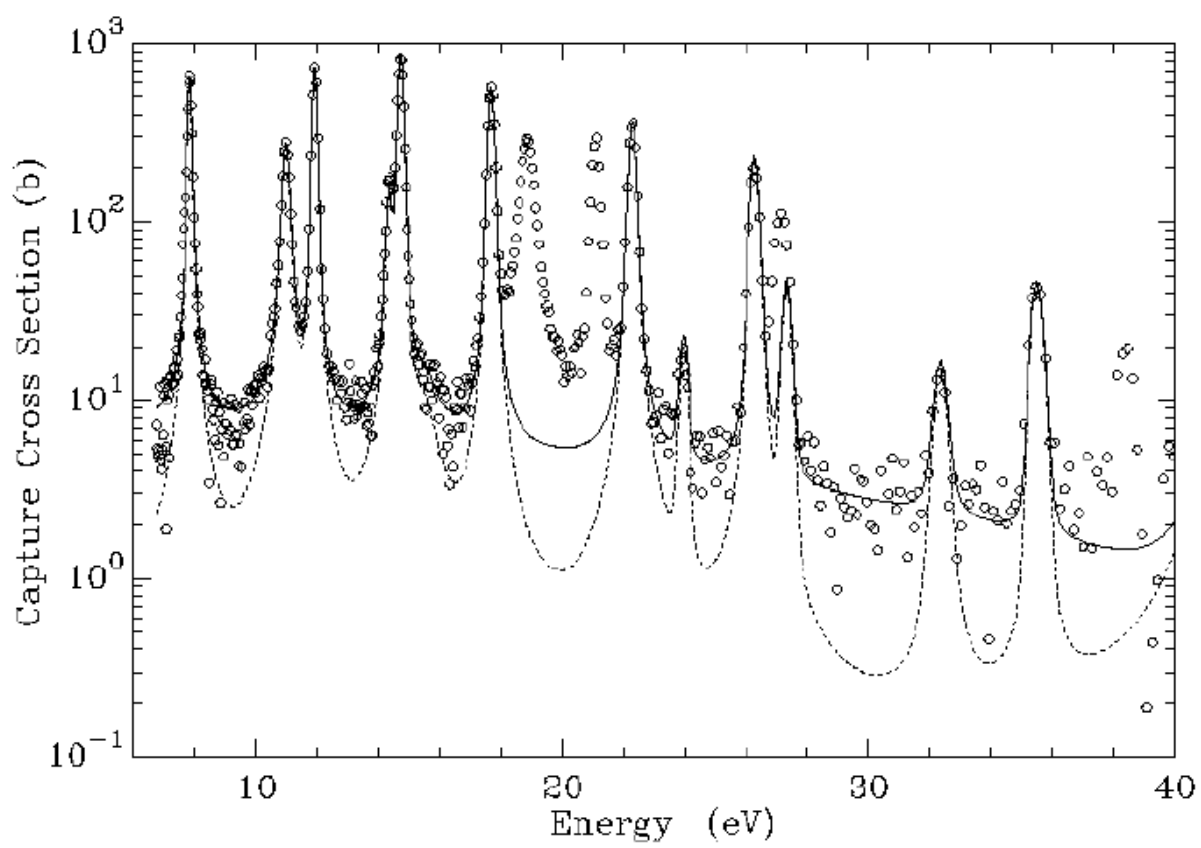

Fig. 1. ${ }^{239} \mathrm{Pu}$ capture cross section in the energy range 6 to $40 \mathrm{eV}$. The experimental data are those of Gwin 1971 not corrected for the impurities contribution. The dashed line represents the cross section calculated by the resonance parameters. The solid line represent the resonance contribution plus a background. 


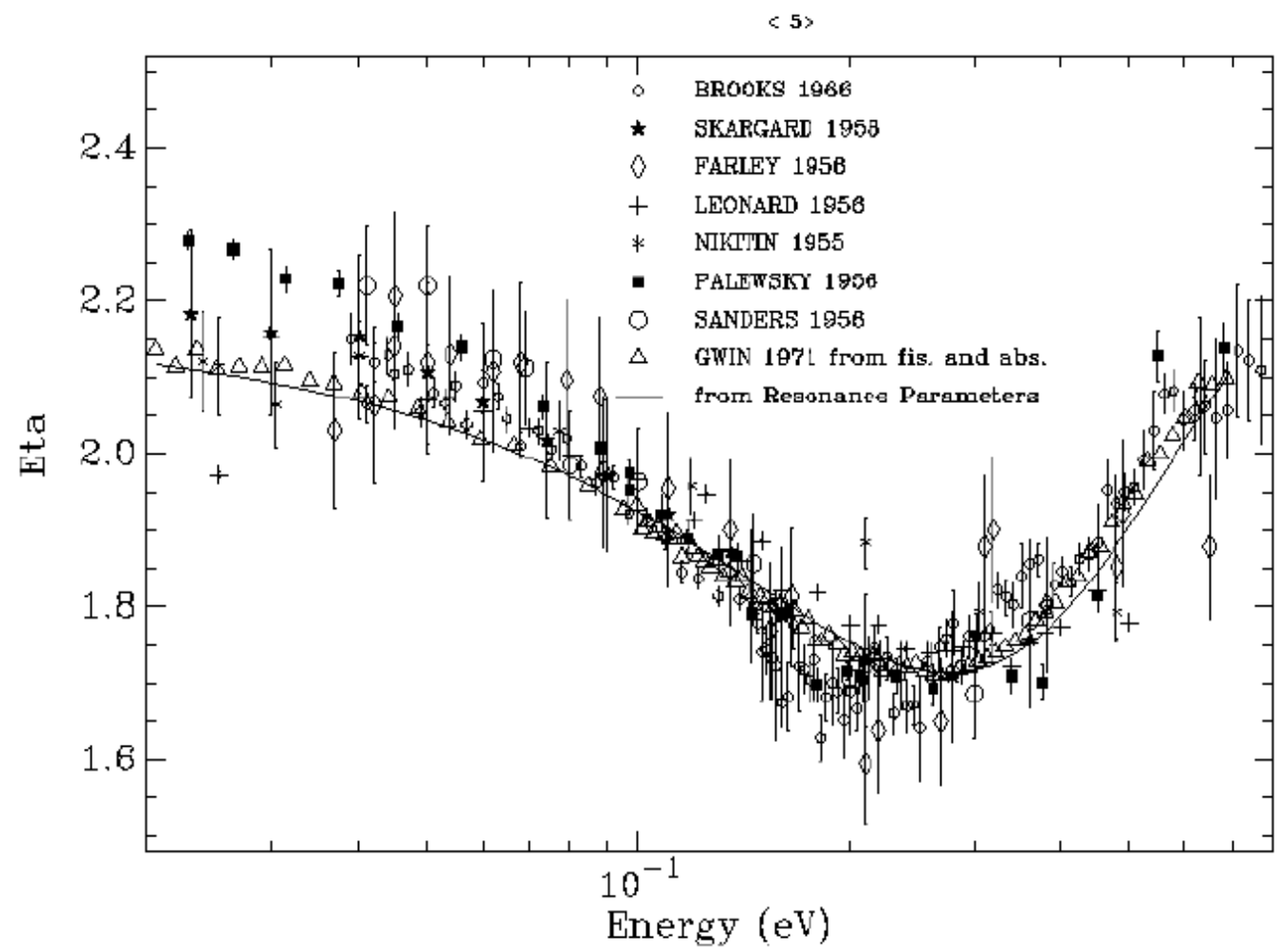

Fig. 2. ${ }^{239} \mathrm{Pu}$ eta $=\boldsymbol{v} \sigma_{\mathrm{f}} / \sigma_{\mathrm{a}}$ in the thermal energy range. The experimental data were normalized to the area of the calculated value curve (solid line on the figure).

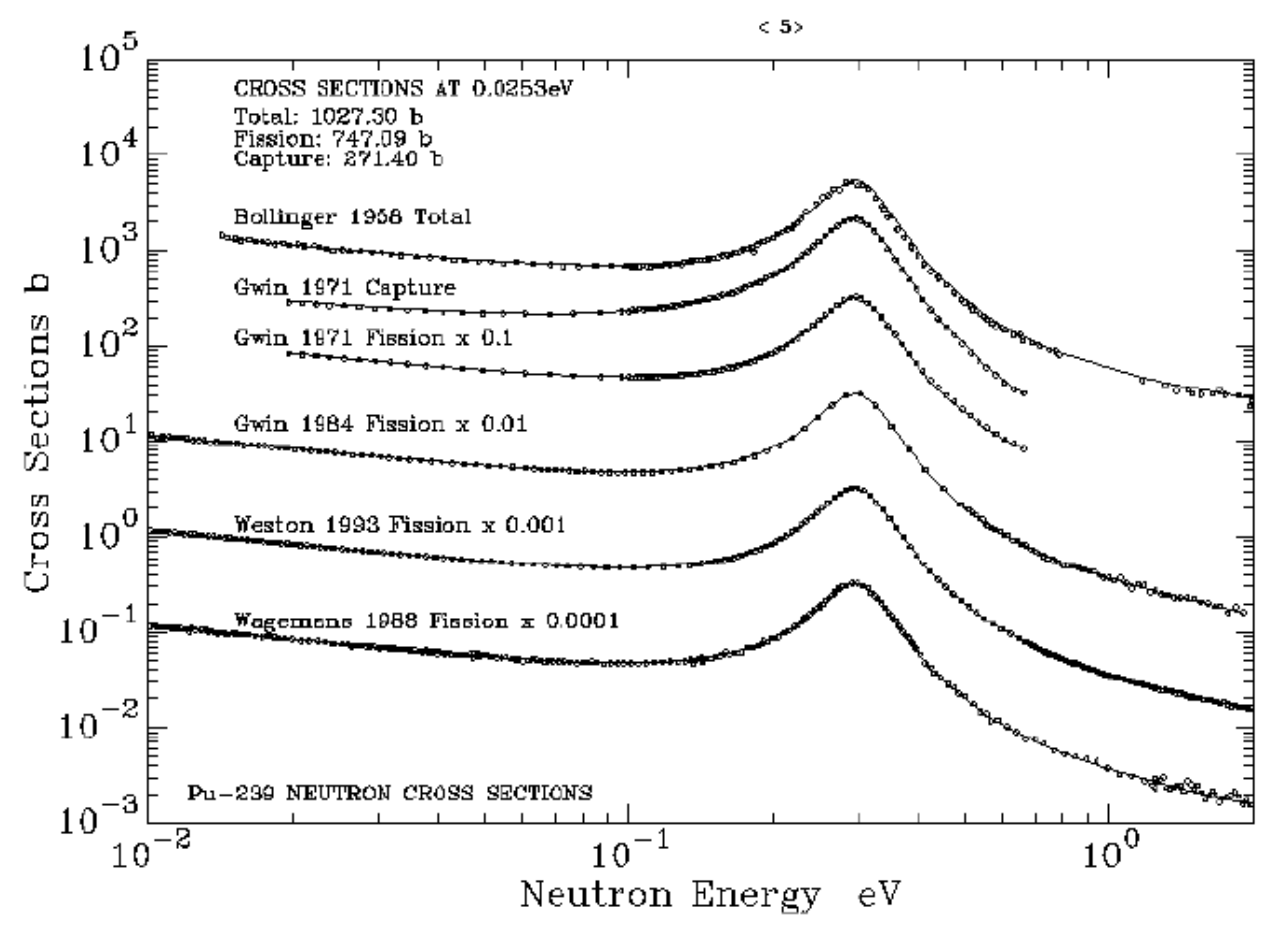

Fig. 3. ${ }^{239} \mathrm{Pu}$ neutron cross sections in the thermal energy range. The solid lines represent the values of the cross sections calculated from the resonance parameters. 


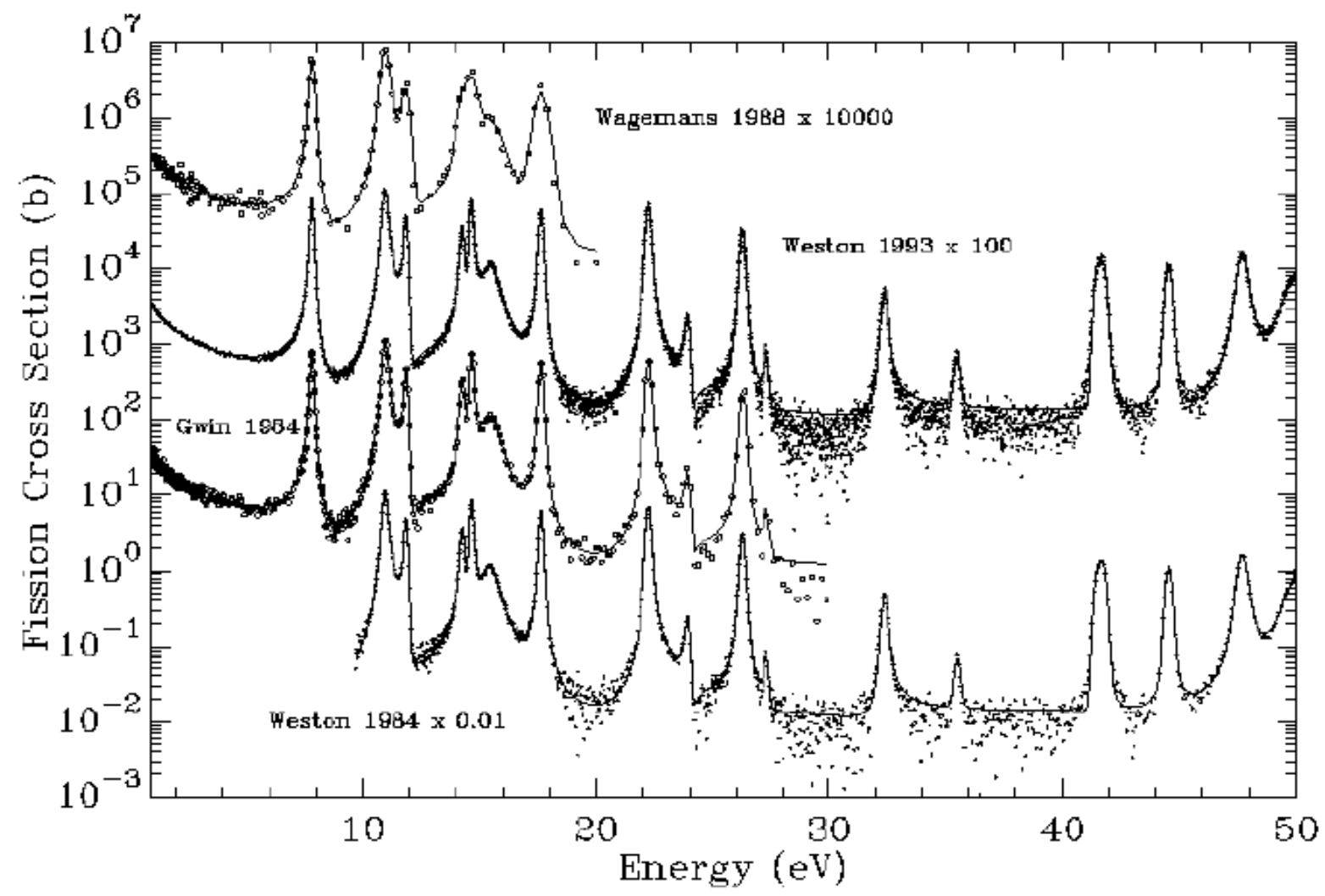

Fig. 4. ${ }^{239} \mathrm{Pu}$ fission cross sections in the energy range 1 to $50 \mathrm{eV}$. The solid lines represent the cross sections calculated by the resonance parameters.

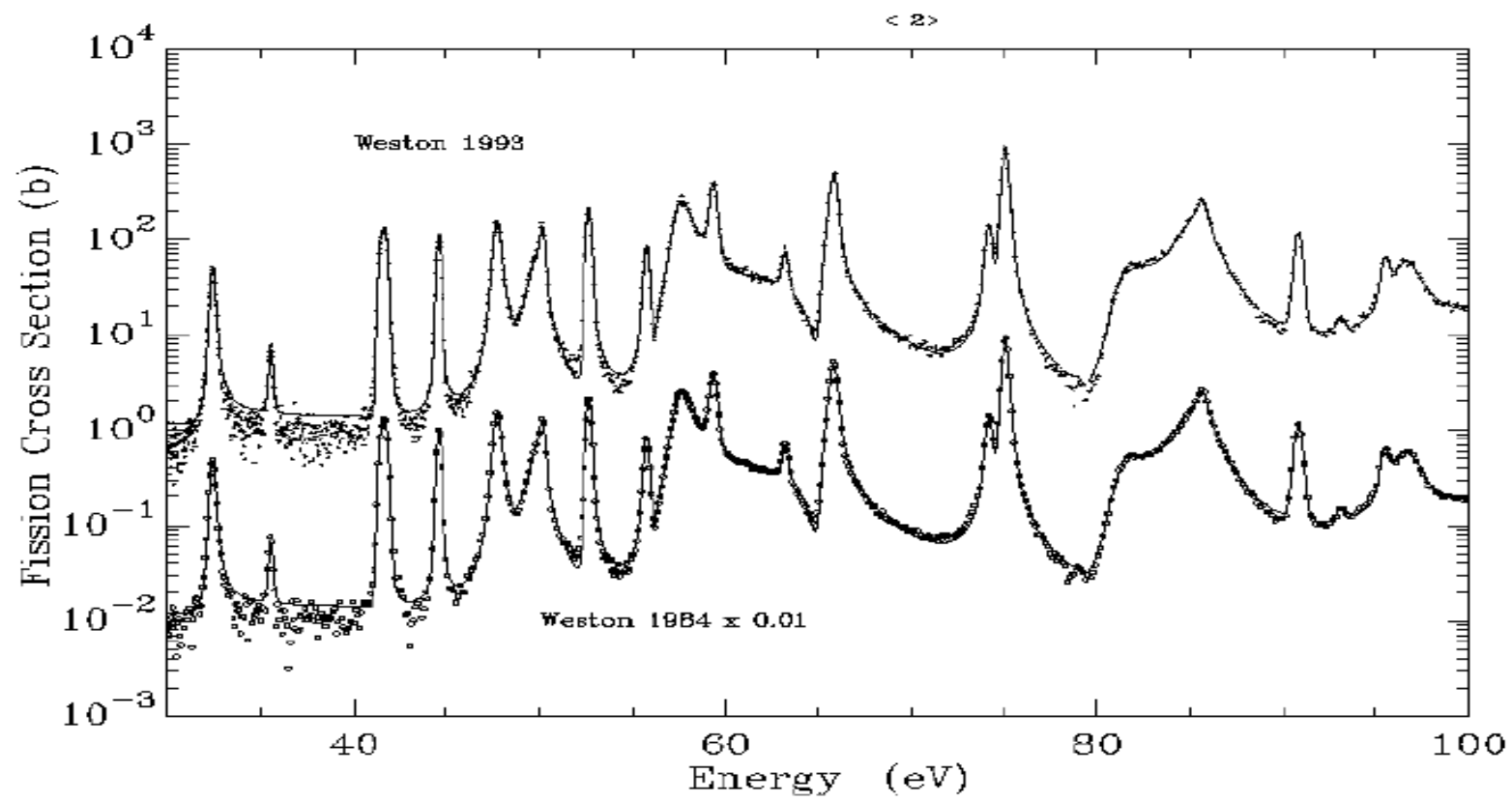

Fig. 5. ${ }^{239} \mathrm{Pu}$ fission cross sections in the energy range 30 to $100 \mathrm{eV}$. The solid lines represent the cross section calculated with the resonance parameters. 


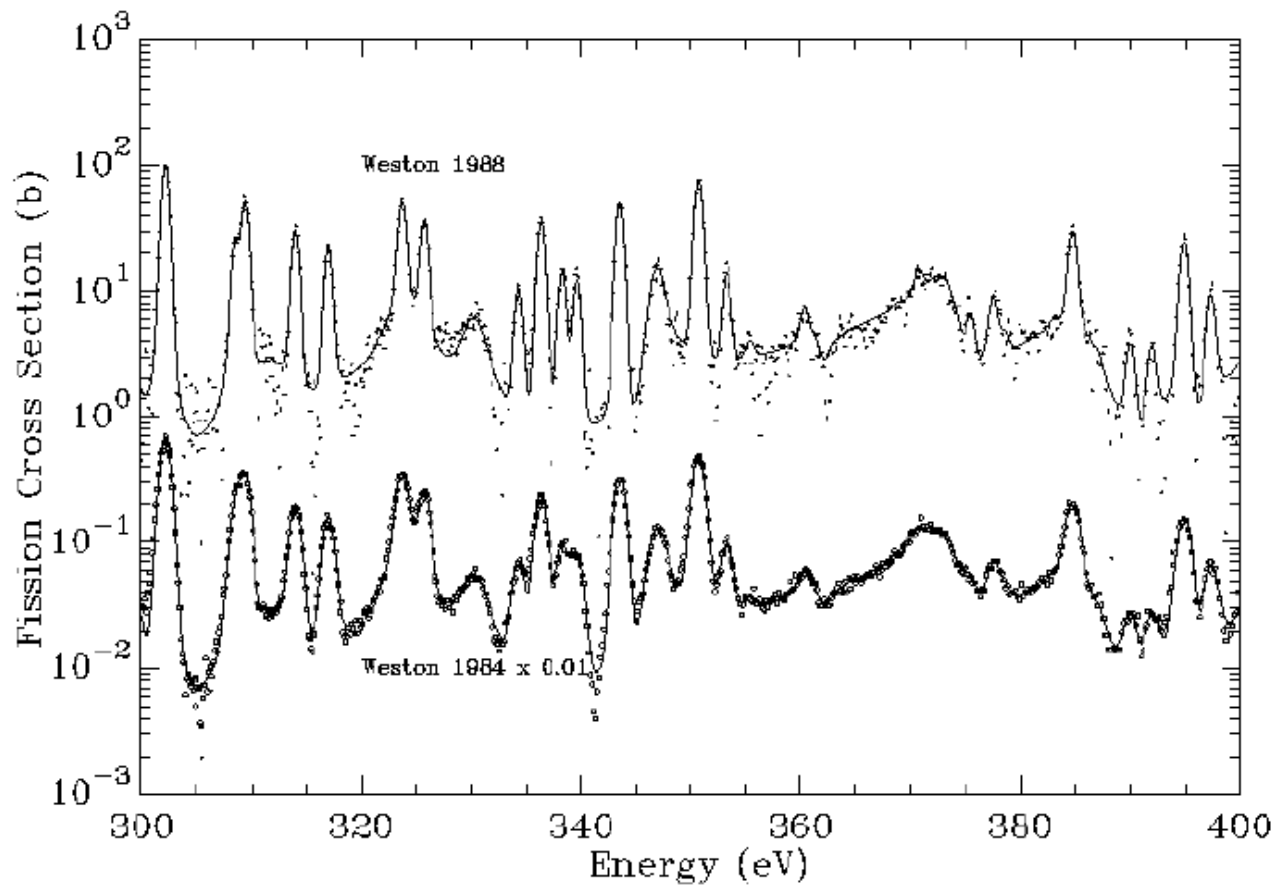

Fig. 6. ${ }^{239} \mathrm{Pu}$ fission cross sections in the energy range 300 to $400 \mathrm{eV}$. The solid lines represent the cross sections calculated with the resonance parameters.

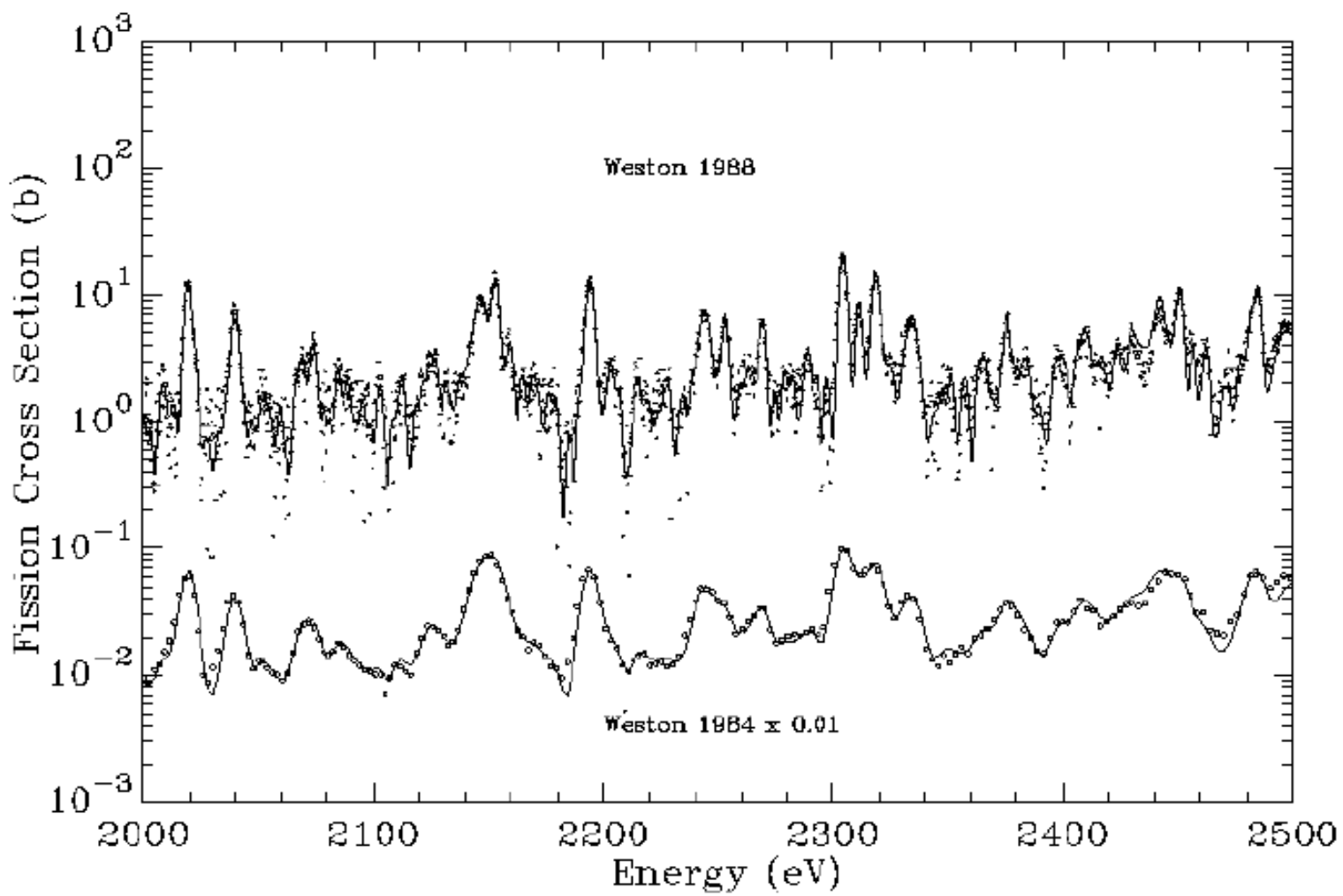

Fig. 7. ${ }^{239} \mathrm{Pu}$ fission cross sections in the energy range 2000 to $2500 \mathrm{eV}$. The solid lines represent the cross sections calculated with the resonance parameters. 

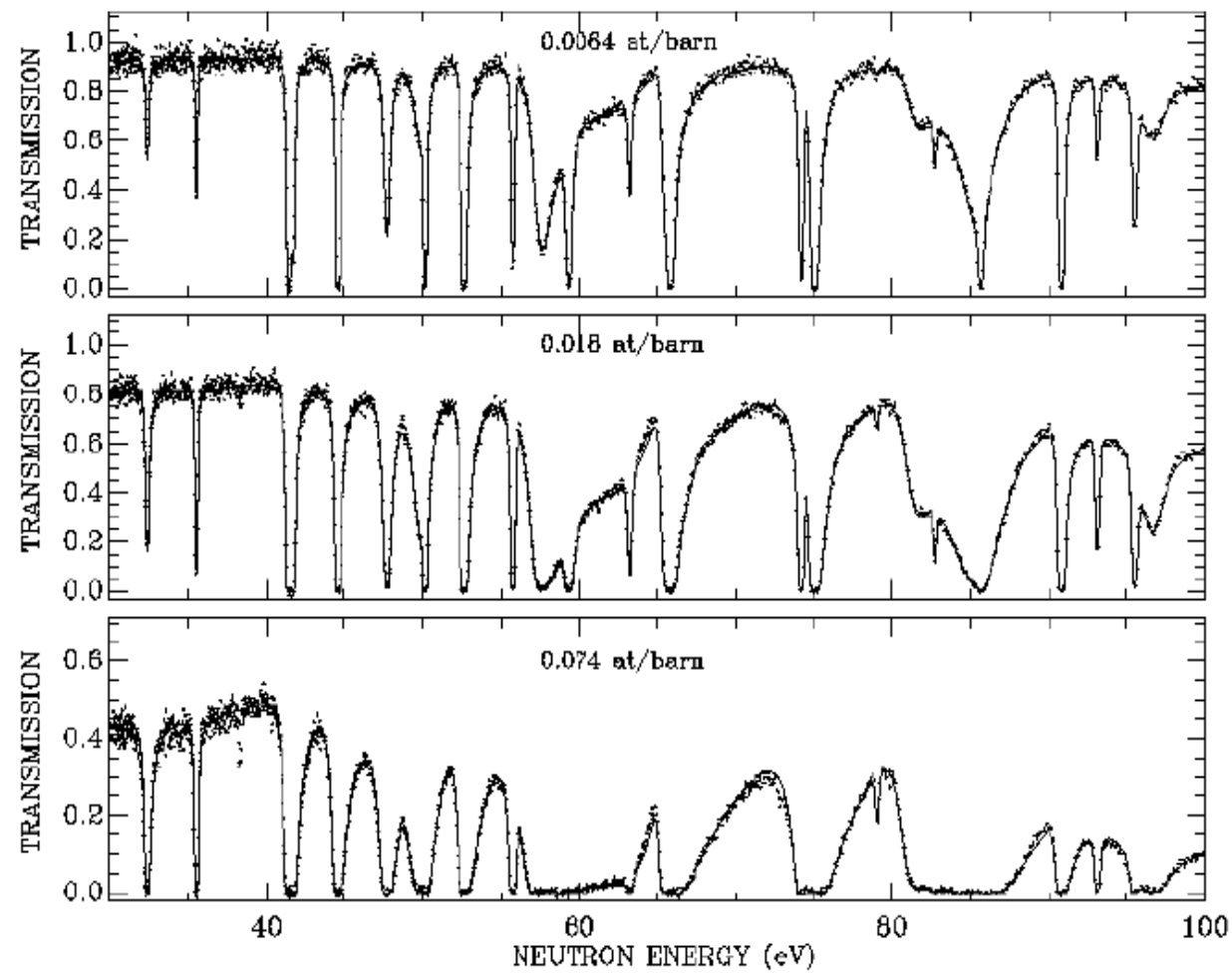

Fig. 8. J. A. Harvey (ref. 18) ${ }^{239}$ Pu neutron transmission in the energy range 30 to $100 \mathrm{eV}$. The solid lines represent the corresponding data calculated with the resonance parameters.

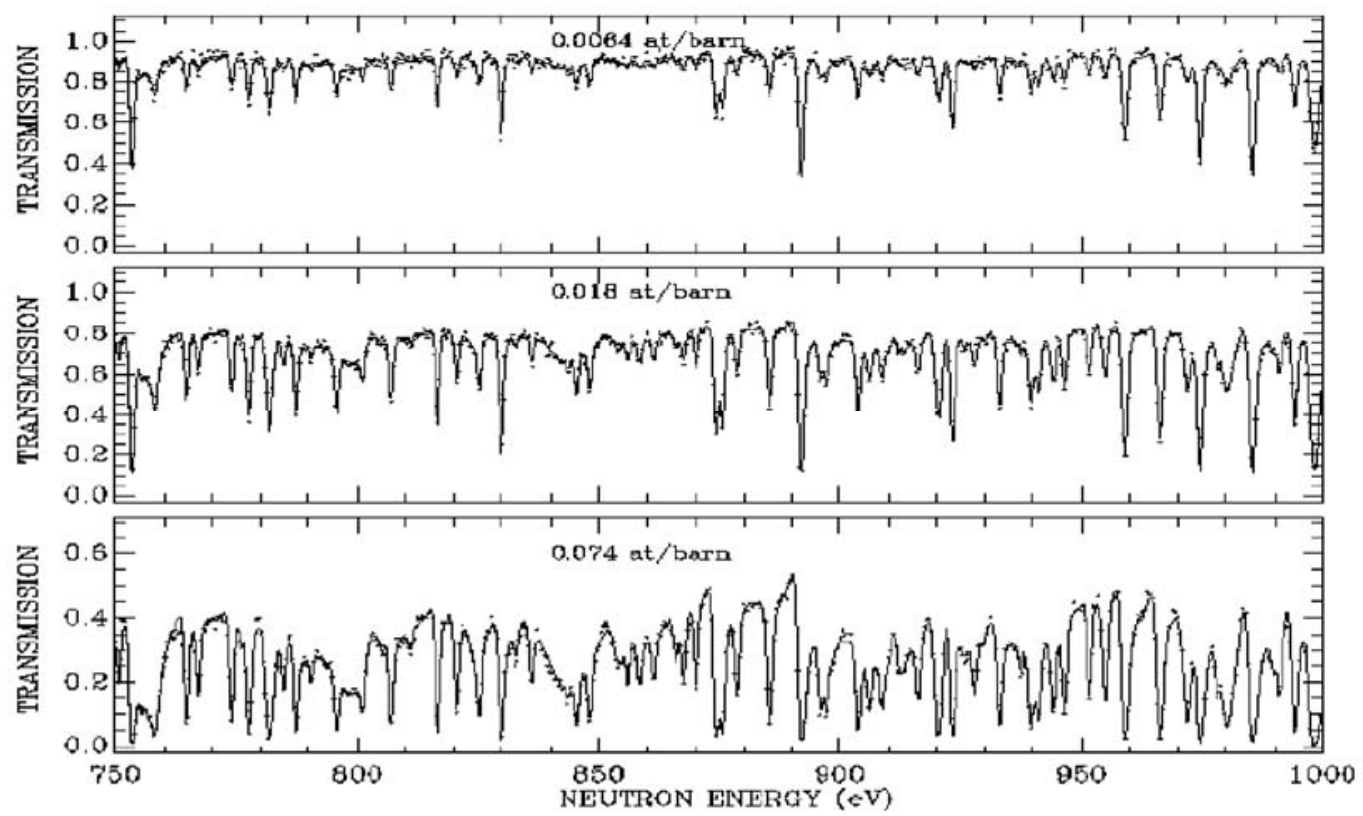

Fig. 9. J. A. Harvey (ref. 18) ${ }^{239} \mathrm{Pu}$ neutron transmissions in the energy range 0.75 to $1.0 \mathrm{keV}$. The solid lines represent the corresponding data calculated with the resonance parameters. 


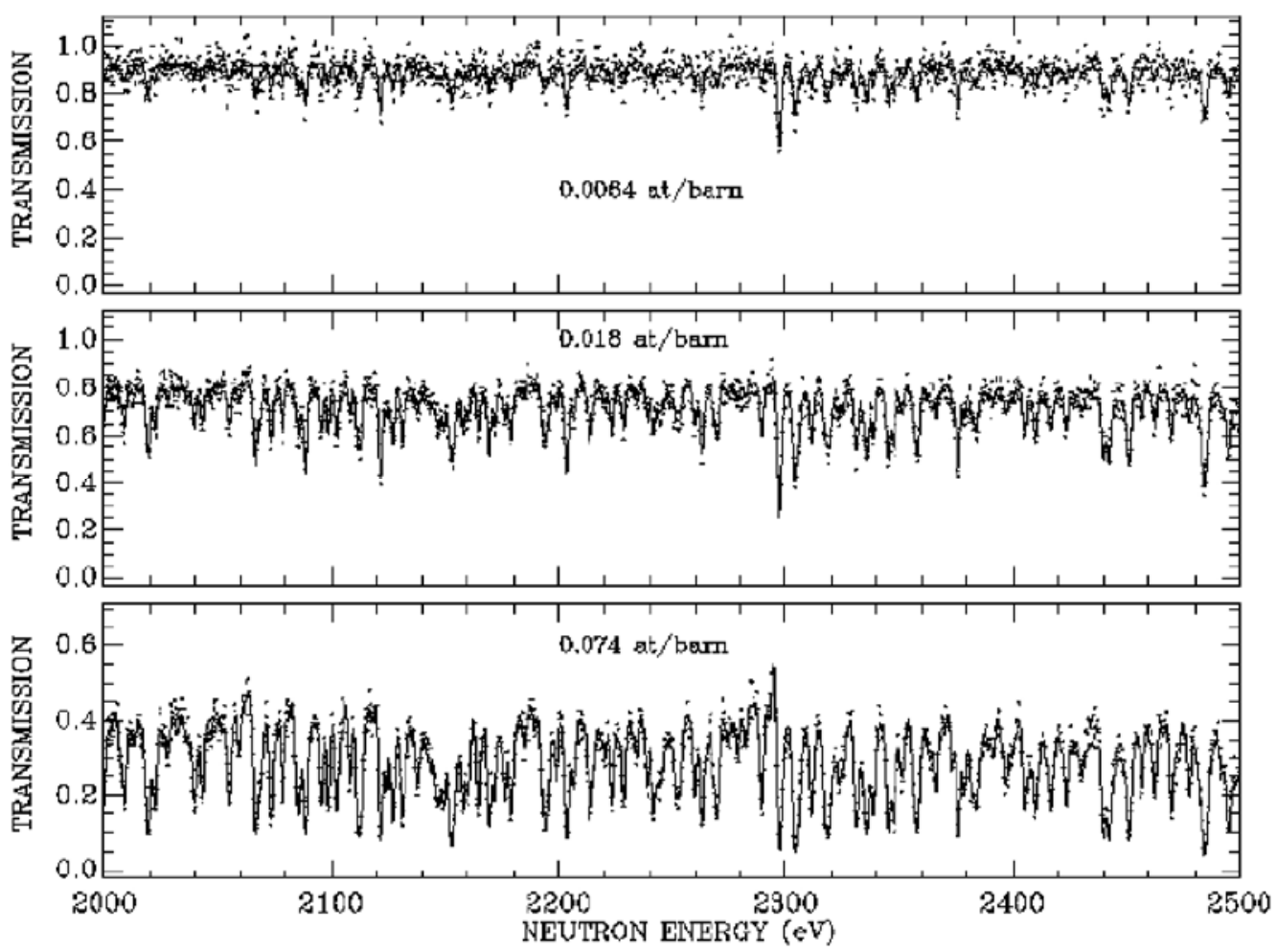

Fig. 10. J. A. Harvey (ref. 18) ${ }^{239} \mathrm{Pu}$ neutron transmission in the energy range 2.0 to $2.5 \mathrm{keV}$. The solid lines represent the corresponding data calculated with the resonance parameters.

\section{THE RESONANCE PARAMETER COVARIANCE MATRIX}

The calculation of the resonance parameter covariance matrix was performed by a single SAMMY run in the energy range $0.01 \mathrm{eV}$ to $2.5 \mathrm{keV}$, including sequentially all the experimental data, with variation of all the resonance parameters. The experimental data base contains experimental data in partial energy ranges; there is no experimental data set covering the entire energy range of the resonances. To alleviate this difficulty for the calculation of a full resonance parameter covariance matrix, "fictive experimental" fission and capture cross sections were generated over the energy range 0 to $2500 \mathrm{eV}$ from the resonance parameters with a resolution at least equivalent to the best experimental resolution. These data were added to the experimental data base at the end of the SAMMY sequences with appropriate normalization and background uncertainties. The analysis was performed with the PUP option of SAMMY. The calculation needed large memory space, due to the handling of matrices of about $10^{6}$ elements. The resulting resonance parameter covariance file was used to calculated the covariance matrix of group cross sections with the PUFF ${ }^{34}$ and ERRORJ ${ }^{35}$ processing codes. Although the PUP version of SAMMY allows the systematic uncertainties of the experimental data to be taken into account, the uncertainties of the calculated group cross sections are still small. Another option of SAMMY allows to multiply, in chosen energy ranges, the errors on the resonance parameters by a suitable coefficient, in order to enhance the uncertainties on the average cross sections. This method does not work for small cross sections between resonances, where the systematic uncertainties, mainly due to the uncertainties in the experimental background evaluation, are important compared to the calculated cross sections. An example of calculated group cross sections and uncertainties is given in Table 9. In the energy range 1 to $7 \mathrm{eV}$, the calculated 
Table 9. Group cross sections (b) and uncertainties calculated by PUFF-IV in the energy range of $0.01 \mathrm{eV}$ to $2.5 \mathrm{keV}$

\begin{tabular}{rrrrrr}
\hline \multicolumn{1}{c}{$\mathbf{E}_{\mathbf{1}}$} & $\mathbf{E}_{\mathbf{2}}$ & \multicolumn{1}{c}{$\boldsymbol{\sigma}_{\boldsymbol{\gamma}}$} & $\boldsymbol{\Delta} \boldsymbol{\sigma}_{\boldsymbol{\gamma}}$ & \multicolumn{1}{c}{$\boldsymbol{\sigma}_{\mathbf{f}}$} & $\boldsymbol{\Delta} \boldsymbol{\sigma}_{\mathbf{f}}$ \\
\hline 0.01 & 0.02 & 336.35 & 5.81 & 975.22 & 10.13 \\
0.02 & 0.03 & 273.35 & 5.33 & 755.99 & 9.42 \\
0.03 & 0.04 & 244.76 & 3.95 & 646.25 & 7.54 \\
0.04 & 0.05 & 229.77 & 3.48 & 579.67 & 6.96 \\
0.05 & 0.10 & 222.89 & 2.99 & 495.26 & 6.07 \\
0.10 & 0.20 & 342.95 & 4.24 & 585.66 & 5.42 \\
0.20 & 0.30 & 1353.61 & 19.13 & 2014.47 & 20.05 \\
0.30 & 1.00 & 201.01 & 4.74 & 337.12 & 4.91 \\
1.00 & 7.00 & 1.31 & 0.02 & 13.46 & 0.31 \\
7.00 & 10.00 & 47.66 & 0.69 & 61.16 & 0.66 \\
10.00 & 12.00 & 117.61 & 0.75 & 249.20 & 1.06 \\
12.00 & 18.00 & 73.51 & 0.58 & 90.72 & 0.56 \\
18.00 & 21.00 & 2.37 & 0.33 & 1.73 & 0.31 \\
21.00 & 28.00 & 32.50 & 0.62 & 44.21 & 0.66 \\
28.00 & 31.00 & 0.34 & 0.01 & 1.44 & 0.07 \\
31.00 & 36.00 & 5.90 & 0.18 & 5.67 & 0.20 \\
36.00 & 40.00 & 0.54 & 0.07 & 1.73 & 0.07 \\
40.00 & 100.00 & 37.34 & 0.80 & 52.73 & 0.07 \\
100.00 & 200.00 & 15.23 & 0.25 & 18.44 & 0.26 \\
200.00 & 500.00 & 9.34 & 0.16 & 11.81 & 0.18 \\
500.00 & 1000.00 & 6.15 & 0.09 & 7.69 & 0.09 \\
1000.00 & 1500.00 & 3.62 & 0.06 & 5.63 & 0.08 \\
1500.00 & 2000.00 & 3.59 & 0.06 & 3.95 & 0.04 \\
2000.00 & 2500.00 & 3.20 & 0.06 & 2.94 & 0.04 \\
\hline
\end{tabular}

capture cross section uncertainty of $0.02 \mathrm{~b}$ is very small compared to estimated systematic uncertainty of about $0.5 \mathrm{~b}$. Due to the interference effects in the fission channels, the cross sections calculated in this energy range depend strongly on the parameters of the bound levels. Differences as large as $0.5 \mathrm{~b}$ are found in cross sections calculated with sets of bound levels fitting accurately the cross sections at $0.0253 \mathrm{eV}$. Since the capture cross sections were not measured in this energy range, the average cross section value remains ambiguous.

In general, a sequential SAMMY analysis of an experimental data base is performed in two stages. In the first stage, an experimental data base is created by taking the data in the EXFOR library or/and directly from the authors of the measurements. This data base could be inconsistent due to large experimental uncertainties. During the SAMMY analysis of this original data base, experimental parameters (normalization corrections, background corrections etc.) are varied. The output of such an analysis then contains fitted values and uncertainties for those experimental parameters. In the second stage, renormalization and background corrections are applied to the experimental data using the information obtained in the first stage; an estimation of the systematic uncertainties can also be made for each data set. The corrected experimental data constitute a consistent data base which can then be represented by a single set of resonance parameters. The SAMMY analysis of this consistent data base will generate a pure Resonance Parameter Covariance Matrix (RPCM). In this case only the statistical uncertainties of the experimental data are propagated in the process of the analysis; systematic uncertainties are ignored. The calculated uncertainties of the average cross sections are statistical uncertainties and are generally small. The analysis of the consistent data base could also be performed by using the PUP option in SAMMY, the systematic uncertainties being introduced on 
"pupped" experimental parameters. The pupped parameters allow SAMMY to calculate the experimental covariance matrix prior to the Bayes analysis. The corresponding RPCM is expected to give larger uncertainties on the average cross sections, because taking into account, in a certain way, the systematic uncertainties of the experimental data.

Tables 10 and Table 11 show examples of different ways of calculating the uncertainties on fission and capture group cross sections in the energy range $0.01 \mathrm{eV}$ to $2.5 \mathrm{keV}$. The "pupped" experimental parameters were the normalization coefficient $\mathrm{k}$, and the background adjustment parameters $\mathrm{a}$ and $\mathrm{b}$; the background being defined as $\mathrm{a}+\mathrm{b} / \mathrm{E} 1 / 2, \mathrm{E}$ is the neutron energy, with the uncertainties $\Delta \mathrm{k}, \Delta \mathrm{a}$, and $\Delta \mathrm{b}$, respectively. In the tables, E1 and E2 are the energy limits of the groups, $\sigma_{\mathrm{f}}$ and $\sigma_{\gamma}$ are the average fission and capture cross sections in each group. The column with the label Stat, contains the uncertainties calculated from the fit of the consistent experimental data base using the current version of SAMMY; they are small and reflect only the experimental statistical uncertainties. The column with the label Pup, contains the uncertainties calculated from the fit with the PUP option in SAMMY. The Pup uncertainties are in general larger than the Stat uncertainties, but are still much smaller than the expected systematic uncertainties. The column with the label Expv contains the uncertainties obtained from a fit using the current version of SAMMY with variation of the experimental parameters. The Expv uncertainties are much larger than the Stat or the Pup uncertainties. They are compatible with the systematic experimental uncertainties. For comparison with what is expected to be realistic uncertainties, the uncertainties were also estimated from the crude relation:

$$
\left[\left(\Delta \mathrm{k} \sigma_{\mathrm{x}}\right)^{2}+(\Delta \mathrm{a}\}^{2}+(\Delta \mathrm{b})^{2} / \mathrm{E}\right]^{1 / 2}
$$

Table 10. ${ }^{239} \mathrm{Pu}$ average fission cross section (b) in energy ranges $E_{1}$ to $E_{2}(\mathrm{eV})$ and associated uncertainties

\begin{tabular}{rrrrrrrc}
\hline $\mathbf{E}_{\boldsymbol{1}}$ & $\mathbf{E}_{\boldsymbol{2}}$ & $\boldsymbol{\sigma}_{\mathbf{f}}$ & Uin & Uout & Expv & Pup & Stat \\
\hline 0.01 & 0.02 & 975.22 & 5.58 & 3.90 & 4.00 & 0.5090 & 0.0685 \\
0.02 & 0.03 & 155.99 & 4.35 & 3.06 & 3.10 & 0.3840 & 0.0517 \\
0.03 & 0.04 & 646.25 & 3.72 & 2.61 & 2.64 & 0.3190 & 0.0429 \\
0.04 & 0.05 & 579.67 & 3.34 & 2.34 & 2.37 & 0.2770 & 0.0374 \\
0.05 & 0.10 & 495.26 & 2.82 & 1.96 & 2.00 & 0.2090 & 0.0284 \\
0.10 & 0.20 & 585.66 & 3.12 & 2.17 & 2.21 & 0.1360 & 0.0188 \\
0.20 & 0.30 & 2014.47 & 10.07 & 7.17 & 7.15 & 0.0952 & 0.0133 \\
0.30 & 1.00 & 337.12 & 1.80 & 1.23 & 1.27 & 0.0510 & 0.0070 \\
1.00 & 7.00 & 13.46 & 0.27 & 0.15 & 0.15 & 0.0143 & 0.0023 \\
7.00 & 10.00 & 61.15 & 0.37 & 0.24 & 0.24 & 0.0082 & 0.0033 \\
10.00 & 12.00 & 249.20 & 1.25 & 0.89 & 0.88 & 0.0092 & 0.0055 \\
12.00 & 18.00 & 90.72 & 0.49 & 0.33 & 0.35 & 0.0544 & 0.0516 \\
18.00 & 21.00 & 1.73 & 0.18 & 0.09 & 0.09 & 0.0068 & 0.0050 \\
21.00 & 28.00 & 44.21 & 0.28 & 0.18 & 0.18 & 0.0041 & 0.0026 \\
28.00 & 31.00 & 1.44 & 0.16 & 0.08 & 0.08 & 0.0042 & 0.0030 \\
31.00 & 36.00 & 5.67 & 0.16 & 0.08 & 0.09 & 0.0175 & 0.0170 \\
36.00 & 40.00 & 1.73 & 0.15 & 0.08 & 0.08 & 0.0034 & 0.0020 \\
40.00 & 100.0 & 52.73 & 0.30 & 0.20 & 0.21 & 0.0322 & 0.0279 \\
100.0 & 200.0 & 18.44 & 0.16 & 0.10 & 0.10 & 0.0113 & 0.0150 \\
200.0 & 500.0 & 11.81 & 0.13 & 0.08 & 0.08 & 0.0063 & 0.0055 \\
500.0 & 1000.0 & 7.69 & 0.12 & 0.09 & 0.08 & 0.0049 & 0.0041 \\
1000.0 & 1500.0 & 5.63 & 0.11 & 0.07 & 0.07 & 0.0046 & 0.0041 \\
1500.0 & 2000.0 & 3.95 & 0.11 & 0.07 & 0.07 & 0.0030 & 0.0027 \\
2000.0 & 2500.0 & 2.94 & 0.11 & 0.07 & 0.07 & 0.0033 & 0.0030 \\
\hline
\end{tabular}


Table 11. ${ }^{239} \mathrm{Pu}$ average capture cross section (b) in energy ranges $\mathrm{E}_{1}$ to $\mathrm{E}_{2}(\mathrm{eV})$ and associated uncertainties

\begin{tabular}{rrrrrrrc}
\hline \multicolumn{1}{c}{$\mathbf{E}_{\boldsymbol{1}}$} & \multicolumn{1}{c}{$\mathbf{E}_{\boldsymbol{2}}$} & $\boldsymbol{\sigma}_{\mathbf{f}}$ & Uin & Uout & Expv & Pup & Stat \\
\hline 0.01 & 0.02 & 336.35 & 6.65 & 4.68 & 4.58 & 0.00770 & 0.00180 \\
0.02 & 0.03 & 273.36 & 5.27 & 3.71 & 3.57 & 0.00568 & 0.00133 \\
0.03 & 0.04 & 244.76 & 4.57 & 3.22 & 3.07 & 0.00461 & 0.00109 \\
0.04 & 0.05 & 229.77 & 4.13 & 2.91 & 2.77 & 0.00393 & 0.00092 \\
0.05 & 0.10 & 222.89 & 3.53 & 2.48 & 2.37 & 0.00281 & 0.00066 \\
0.10 & 0.20 & 342.95 & 3.98 & 2.79 & 2.73 & 0.00164 & 0.00038 \\
0.20 & 0.30 & 1353.61 & 13.52 & 9.47 & 9.54 & 0.00103 & 0.00024 \\
0.30 & 1.00 & 201.01 & 2.35 & 1.65 & 1.60 & 0.00044 & 0.00011 \\
1.00 & 7.00 & 1.31 & 0.62 & 0.44 & 0.33 & 0.00007 & 0.00004 \\
7.00 & 10.00 & 47.66 & 0.69 & 0.49 & 0.42 & 0.00007 & 0.00007 \\
10.00 & 12.00 & 117.61 & 1.25 & 0.87 & 0.85 & 0.00015 & 0.00014 \\
12.00 & 18.00 & 73.51 & 0.86 & 0.60 & 0.56 & 0.00318 & 0.00300 \\
18.00 & 21.00 & 2.37 & 0.44 & 0.31 & 0.23 & 0.00016 & 0.00015 \\
21.00 & 28.00 & 32.50 & 0.55 & 0.39 & 0.34 & 0.00004 & 0.00004 \\
28.00 & 31.00 & 0.34 & 0.41 & 0.29 & 0.22 & 0.00015 & 0.00015 \\
31.00 & 36.00 & 5.90 & 0.41 & 0.29 & 0.22 & 0.00756 & 0.00750 \\
36.00 & 40.00 & 0.54 & 0.40 & 0.28 & 0.22 & 0.00005 & 0.00004 \\
40.00 & 100.0 & 37.34 & 0.54 & 0.38 & 0.35 & 0.00259 & 0.00237 \\
100.0 & 200.0 & 15.23 & 0.37 & 0.26 & 0.23 & 0.00186 & 0.00184 \\
200.0 & 500.0 & 9.34 & 0.34 & 0.24 & 0.22 & 0.00056 & 0.00055 \\
500.0 & 1000.0 & 6.15 & 0.32 & 0.22 & 0.21 & 0.00086 & 0.00086 \\
1000.0 & 1500.0 & 3.62 & 0.31 & 0.22 & 0.20 & 0.00044 & 0.00044 \\
1500.0 & 2000.0 & 3.59 & 0.31 & 0.22 & 0.20 & 0.00027 & 0.00027 \\
2000.0 & 2500.0 & 3.20 & 0.30 & 0.21 & 0.20 & 0.00064 & 0.00064 \\
\hline
\end{tabular}

which is a quadratic combination of the uncertainties on the cross sections due to the uncertainties on $\mathrm{k}$, a, and $\mathrm{b}$. The column with the label Uin contains these estimated uncertainties corresponding to the input values of $\mathrm{k}$, $\mathrm{a}$, and $\mathrm{b}$ in the corresponding SAMMY sequence, and the column with the label Uout contains the estimated uncertainties corresponding to the output values, i.e., those that are in the covariance matrix. The conclusion is straightforward: only the Expv uncertainties are realistic: they are practically the same than the Uout values.

In SAMMY, the calculation of the uncertainties or variances of group or averaged cross sections is performed according to the relations (V C1.9) and (V C1.10) of the SAMMY manual, ${ }^{10}$ which are summations of quantities including all the elements of the non diagonal RPCM. In the PUP option of SAMMY the "pupped" experimental parameters are not in the RPCM. Therefore the corresponding uncertainties and correlations are not explicitly taken into account in the calculation of the variance and covariance of the average cross sections. Among the data shown in Tables 10 and 11, only the Expv uncertainties are calculated with a RPCM including explicitly variances and co-variances related to experimental parameters. Unfortunately such covariance matrices cannot be used in the ENDF format. The uncertainties shown in Table 9 is the result of a make-shift to alleviate the deficiencies of the ENDF formats. 


\section{CONCLUSIONS}

The ${ }^{239} \mathrm{Pu}$ resonance parameters have been reevaluated in the energy range thermal to $2500 \mathrm{eV}$. The three uncorrelated energy ranges of the previous evaluations were merged in a single range. The most recent fission cross section measurements of Weston et al. and of Wagemans et al. were added to the experimental data base, allowing a more accurate normalization of the experimental fission data. A complete resonance parameter covariance matrix was obtained in the energy range 0 to $2500 \mathrm{eV}$. This large covariance matrix was processed with the code PUFF-IV and allowed the calculation of reasonable uncertainties of the group averaged cross sections.

Propagating the systematic uncertainties in all stages of the evaluation was not straightforward. In addition to the variances and co-variances of the resonance parameters the RPCM should also contain the variances and co-variances related to the experimental parameters, needed for a realistic calculation of the systematic uncertainties of the average cross sections. The RPCM including such parameters is not provided in the ENDF format. Palliative methods have to be used to compensate the lack of adequate format. In the present evaluation, the uncertainties in the RPCM were multiplied by suitable coefficients in order to enhance the uncertainties on the group cross sections. The result is not satisfactory in some energy ranges. The RPCM is stored in file 32 of the ENDF format. In general the resolved resonance energy range of the file 3 contains no cross section values, or the values needed to represent the part of the cross sections that could not be described by the resonance parameters (direct capture, contribution of the missed p- or d-wave resonances etc...). The covariance matrix associated to file 3 is stored in the file 33 and contains the variances and co-variances of the cross sections in the energy range above the resolved energy range. A file 33 could also be generated in the resolved resonance range, that contains the variances and co-variances associated to the experimental systematic uncertainties lacking in the RPCM. The processing of two covariance matrices in the resolved energy range by ERRORJ or PUFF IV, is possible without additional computation capability in these codes. The feasibility of this method has already been tested in the evaluation of the ${ }^{55} \mathrm{Mn}$ resonance parameters. ${ }^{36}$

\section{REFERENCES}

1. H. Derrien et al., ORNL/TM-10098, 1986.

2. H. Derrien and G. De Saussure, ORNL/TM-10986, 1989.

3. H. Derrien and G. De Saussure, ORNL/TM-11490, 1990.

4. H. Derrien and G. De Saussure, Nucl. Sci. Eng. 106, 434 (1990).

5. H. Derrien, J. Nucl. Sci. Tech. 30, 485 (1993).

6. A. D. Carlson et al., NISTIR, ENDF-351, 1992.

7. L. W. Weston, J. H. Todd, and H. Derrien, Nucl. Sci. Eng. 115, 164 (1993).

8. C. Wagemans et al., Nucl. Sci. Eng. 115, 173 (1993).

9. L. C. Leal, H. Derrien, N. M. Larson, et al., "ORNL Methodology for Covariance Generation for Sensitivity/Uncertainty Analysis," p-25-29 in Proceedings of the 8th International Conference on Nuclear Criticality Safety" (ICNC 2007), Vol. II, May 28-June 1, 2007, St. Petersburg, Russia, 2007.

10. N. M. Larson, ORNL/TM-9179/R7, 2006.

11. R. Gwin et al., Nucl. Sci. Eng. 45, 25 (1971).

12. R. Gwin et al., Nucl. Sci. Eng. 59, 79 (1976).

13. R. Gwin et al., Nucl. Sci. Eng. 88, 37 (1984).

14. L. W. Weston and J. H. Todd, Trans. Am. Nucl. Soc. 480 (1972).

15. L. W. Weston and J. H. Todd, Nucl. Sci. Eng. 88, 567 (1984).

16. L. W. Weston and J. H. Todd, Nucl. Sci. Eng. 111, 415 (1992). 
17. J. A. Harvey, private communication, Oak Ridge National Laboratory, 1985.

18. J. A. Harvey, Proc. Int. Conf. Nuclear Data for Science and Technology, Mito, Japan, May 30-June 3, 1988.

19. C. Wagemans et al., Proc. Int. Conf. Nuclear Data for Science and Technology, Mito, Japan, May 30-June 3, 1988.

20. L. M. Bollinger, R. E. Cote, and G. E. Thomas, Bul. Am. Phys. Soc. 1, 187(k5), 1956.

21. R. R. Spencer et al., Nucl. Sci. Eng. 96, 318 (1987).

22. International Exchange Format for compiled experimental neutron cross section (EXFOR).

23. J. J. Griffin, Symposium on Physic and Chemistry of Fission, Salzburg, March 1965, Vol. 1, p. 23, 1965.

24. S. F. Mughabghag, Atlas of Neutron Resonances, 5th Edition, Elsevier, Amsterdam, Netherland, 2006.

25. M. G. Shomberg et al., Proc. Int. Conf. Nuclear Data for Reactors, Vol. 1, p. 315, Helsinki, International Atomic Energy Agency, Vienna, 1970.

26. S. Ya. Nikitin et al., AEC-TR-2435, 1956, Translation of a Moscow Conf., p. 87, 1955.

27. J. E. Sanders, private communication to BNL/NNDC, Harwell, UK, 1956.

28. R. R. Leonard, E. J. Seppi, and W. J. Frieser, HW-44526, p. 47, Hanford, Richland, Washington, 1956.

29. H. Palewski et al., J. Nucl. Energy 3, 177 (1956).

30. H. N. Skarsgard and C. J. Kenward, J. Nucl. Energy 6, 212 (1958).

31. F. D. Brooks et al., AERE-M-1709, Harwell, UK, 1966.

32. F. J. M. Farley, J. Nucl. Energy 3, 33 (1956).

33. A. Santamarina et al., Improvements of the 239Pu Evaluation for JEFF-3, JEF/DOC-1158 (November 2006).

34. D. Wiarda and M. E. Dunn, PUFF-IV, ORNL/TM-2006/147, 2006.

35. K. Kosako and N. Yanano, Specialist Meeting of Reactor Group Constants, JAERIConf 2001-009, ed. J. Katakura, JAERI, Tokai, Japan, 2001.

36. D. Wiarda, ORNL, personal communication with H. Derrien, 2008. 


\section{INTERNAL DISTRIBUTION}

1. G. Arbanas

2. H. Derrien

3. M. E. Dunn, 5700, MS 6171

4. J. C. Gehin, 5700, MS 6172

5. K. H. Guber, 6010, MS 6356

6. N. M. Larson, 5700, MS 6171

7. L. C. Leal, 5700, MS 6171

8. J. M. Norman, 4500N, MS 6227
9. C. V. Parks, 5700, MS 6171

10. R. O. Sayer, 5700, MS 6171

11. J. C. Wagner, 5700, MS 6170

12. R. M. Westfall, 5700, MS 6170

13. D. Wiarda, 5700, MS 6171

14. M. L. Williams, 5700, MS 6170

15. ORNL OTIC-RC, 6011, MS 6283

\section{EXTERNAL DISTRIBUTION}

16. P. Blaise, DER/SPRC/LEPH, Batiment 230, Centre d'Etudes de CADARACHE, 13108 Saint Paul-lez-Durance, France

17. Olivier Bouland, CEA/DEN/DER/SPRG/LEPh, Cadarache Centre, F-13108 Saint-Paul-LezDurance Cedex, France

18. D. Cabrilla, U.S. Department of Energy, NE-43/Germantown Building, 1000 Independence Ave., Washington, DC 20585

19. Allan D. Carlson, Ionizing Radiation Division, National Institute of Standard and Technology

20. D. E. Carlson, U.S. Nuclear Regulatory Commission, Reactor and Plant System Branch, Division of System Research, Office of Nuclear Regulatory Research, MS T-10 G6, Rm. T-10, 17, Washington, DC 20555-0001

21. M. B. Chadwick, Los Alamos National Laboratory, MS B243 T-16, Los Alamos, NM 87545

22. J. Chang, Korea Atomic Energy Research Inst., Nuclear Data Evaluation Lab., P.O. Box 105, Yusang, Taejon 305-600, Korea

23. Arnauld Courcelle, CEA/DEN/DER/SPRG/LEPh, Cadarache Centre, F-13108 Saint-Paul-LezDurance Cedex, France

24. Patrick Cousinou, Institut de Radioprotection et de Surete Nucleaore, B.P. 17, 92262 Fontenayaux-Roses, France

25. Y. Danon, Gaerttner LINAC Laboratory, Rensselaer Polytechnic Institute, Department of Environmental and Energy Engineering, Troy, NY 12180-3590

26. Jean-Pierre Delaroche, Department de Physique Theorique et Appliquee CEA/DAM, B.P. 12, F91680, Bruyere-Le Chatel, France

27. Emmeric Dupont, CEA/DEN/DER/SPRG/LEPh, Cadarache Centre, F-13108 Saint-Paul-LezDurance Cedex, France

28. J. R. Felty, Science Applications Intl. Corp., 2418 N. Dickerson St., Arlington, VA 22207

29. S. C. Frankle, X-TM, MS B226, Los Alamos National Laboratory, Los Alamos, NM 87545

30. W. Furman, Frank Laboratory of Neutron Physics, JINR, Dubna, Russia

31. C. Gould, North Carolina State University, Physics Dept., Box 8202, Raleigh, NC 27695-8202

32. F. Gunsing, Centre D’Etudes De Saclay, F-Saclay-91191, Gif-sur-Yvette Cedex, France

33. Robert Haight, Los Alamos National Laboratory, Los Alamos, NM 87545

34. A. Hasegawa, Nuclear Data Center, Japan Atomic Energy Research Institute, Tokai-mura, Nakagun, Ibaraki-ken 319-11, Japan

35. M. Herman, National Nuclear Data Center, Bldg. 197D Brookhaven National Laboratory, Upton, NY 11973-5000 
36. M. Jaeger, Inst. F. Strahlenphysik, Allmandring 3, Stuttgart D-70569, Germany

37. N. Janeva, Bulgarian Academy of Sciences, 72, Boul, Tzarigradsko shosse, Sofia 1784, Bulgaria

38. H. C. Johnson, U.S. Department of Energy, EM-21 Forrestal, 1000 Independence Ave., SW., Washington, DC 20585

39. Toshihiko Kawano, Los Alamos National Laboratory, MS B243, T-16, Los Alamos, NM 87545

40. Lambros Lois, U.S. Nuclear Regulatory Commission, 08 E23, 11555 Rockville Pike, Rockville, MD 20852-2746

41. G. Leinweber, Gaerttner LINAC Laboratory, Rensselaer Polytechnic Institute, Dept. of Environmental and Energy Engineering, Troy, NY 12180-3590

42. R. Little, Los Alamos National Laboratory, X-TM, MS B226, Los Alamos, NM 87545

43. C. Lubitz, Knolls Atomic Power Laboratory, P.O. Box 1072, Schenectady, NY 12301

44. R. E. MacFarlane, Los Alamos National Laboratory, T-2, MS B243, Los Alamos, NM 87545

45. Robert McBroom, U.S. Department of Energy, Oak Ridge Operations Office, 200 Administration Road, Oak Ridge, TN 37831

46. Jerry McKamy, NA-171, Germantown Building, U.S. Department of Energy, 1000 Independence Ave., SW, Washington, DC 20585-1290

47. Richard D. McKnight, Nuclear Engineering Division-Bldg. 208, Argonne National Laboratory, 9700 S. Cass Ave., Argonne, IL 60439

48. Russell D. Mosteller, Applied Physics Division, Los Alamos National Laboratory, NM 87545

49. C. Mounier, CEN Saclay, DMT/SERMA/LENR, 91191 Gif Sur Yvette Cedex, France

50. M. C. Moxon, 3 Hyde Copse, Marcham, Abingdon, Oxfordshire, England

51. S. F. Mughabghab, Brookhaven National Laboratory, Advanced Technology Building 197d, Upton, NY 11973-5000

52. Mark Nikolaev, State Scientific Center of the Russian Federation, Institute for Physics and Power Engineering, Bondarenko Sq, Obninsk, Kaluga Region, 249020, Russian Federation

53. C. Nordborg, OECD/NEA, Le Seine St-Germain 12, Boulevard des Iles, 92130, Issy-lesMoulineaux, France

54. P. Oblozinsky, National Nuclear Data Center, Bldg. 197D Brookhaven National Laboratory, Upton, NY 11973-5000

55. S. Y. Oh, Nuclear Data Evaluation Lab. Korea Atomic Energy Research Institute, P.O. Box 105, Yusung Taejon, 305-600 Korea

56. A. Plompen, Institute for Reference Materials and Measurements, Retieseweg 111, 2240 Geel, Belgium

57. A. Popov, Frank Laboratory of Neutron Physics, Joint Institute for Nuclear Research, RU-141980 Dubna, Moscow Region, Russia

58. C. Raepsaet, CEN Saclay, DMT/SERMA/LEPP, 91191, Gif Sur Yvette Cedex, France

59. Pascal Romain, Department de Physique Theorique et Appliquee, CEA/DAM, B.P. 12, F91680, Bruyere-Le Chatel, France

60. Veronique Rouyer, Institut de Radioprotection et de Surete Nucleaire, BP 17, 92262 Fontenayaux Roses, France

61. P. Rullhusen, Institute for Reference Materials and Measurements, Retieseweg 111, 2240 Geel, Belgium

62. P. Schillebeeckx, Institute for Reference Materials and Measurements, Retieseweg 111, 2240 Geel, Belgium

63. O. A. Shcherbakov, Petersburg Nuclear Physics Institute, 188350 Gatchina, Leningrad District, Russia

64. Shibata, Nuclear Data Center, Japan Atomic Energy Research Institute, Tokai-mura Naka-gun, Ibaraki-ken 319-11, Japan

65. Patrick Talou, Los Alamos National Laboratory, MS B283, T-16, Los Alamos, NM 87545. 
66. H. Takano, Nuclear Data Center, Japan Atomic Energy Research Institute, Tokai-mura, Nakagun, Ibaraki-ken 319-11, Japan

67. Anatoly Tsiboulia, State Scientific Center of the Russian Federation, Institute for Physics and Power Engineering, Bondarenko Sq. Obninsk, Kaluga Region, 249020, Russian Federation

68. J. J. Wagschal, Racah Institute of Physics, The Hebrew University of Jerusalem, 91904, Jerusalem, ISRAEL

69. K. Yoo, Korea Atomic Energy Research Inst., Nuclear Data Evaluation Lab., P.O. Box 105, Yusung, Taejon 305-600, Korea

70. Phillip G. Young, Los Alamos National Laboratory, MS B243 T-16, Los Alamos, NM 87545 
